\title{
CHARACTERIZATION OF POROUS CARBON FIBERS AND RELATED MATERIALS
}

\section{FINAL REPORT}

July 15, 1996

AECEIVED

AUG 081996

\author{
Report Prepared by \\ E. Loren Fuller, Jr. \\ Principal Investigator \\ Department of Geological Sciences \\ The University of Tennessee \\ Knoxville TN 37996-1410 \\ under \\ Subcontract Number 11X-ST645(UT-3) \\ for
}

OAK RIDGE NATIONAL LABORATORY

Oak Ridge TN 37831-6088

Managed by

LOCKHEED MARTIN ENERGY RESEARCH CORP.

for the

UNITED STATES DEPARTMENT OF ENERGY

under contract DE-AC05-96OR22464 
This report has been reproduced directly from the best available copy.

Available to DOE and DOE contractors from the Office of Scientific and Technical Information, P.O. Box 62, Oak Ridge, TN 37831; prices available from (423) 576-8401.

Available to the public from the National Technical Information Service, U.S. Department of Commerce, 5285 Port Royal Rd., Springfield, VA 22161.

This report was prepared as an account of work sponsored by an agency of the United States Government. Neither the United States Government nor any agency thereof, nor any of their employees, makes any warranty, expressed or implied, or assumes any legal liability or responsibility for the accuracy, completeness, or usefulness of any information, apparatus, product, or process disclosed, or represents that its use would not infringe privately owned rights. Reference herein to any specific commercial product, process, or service by trade name, trademark, manufacturer, or otherwise, does not necessarily constitute or imply its endorsement, recommendation, or favoring by the United States Government or any agency thereof. The views and opinions of authors expressed herein do not necessarily state or reflect those of the United States Government or any agency thereof. 


\section{DISCLAIMER}

Portions of this document may be illegible in electronic image products. Images are produced from the best available original document. 
ORNL/Sub/95-ST645/01

\title{
CHARACTERIZATION OF POROUS CARBON FIBERS AND RELATED MATERIALS
}

\section{- FINAL REPORT}

July 15,1996

Research sponsored by the U.S. Department of Energy, Office of Fossil Energy

Advanced Research and Technology Development Materials Program

\author{
Report Prepared by \\ E. Loren Fuller, Jr. \\ Principal Investigator \\ Department of Geological Sciences \\ The University of Tennessee \\ Knoxville TN 37996-1410 \\ under \\ Subcontract Number 11X-ST645(UT-3) \\ for \\ OAK RIDGE NATIONAL LABORATORY
}

Oak Ridge TN 37831-6088

Managed by

LOCKHEED MARTIN ENERGY RESEARCH CORP.

for the

UNITED STATES DEPARTMENT OF ENERGY under contract DE-AC05-960R22464 


\section{TABLE OF CONTENTS}

FINAL REPORT

PAGE

TABLE OF CONTENTS

1

LIST OF TABLES

2

LIST OF FIGURES

3

SUMMARY

INTRODUCTION

6

EQUIPMENT AND EXPERIMENTS

RESULTS AND DISCUSSION

Analyses of Sorption of Commercial Activated Carbon $\quad 10$

Characterization of Coals and Coal Extracts 21

Activation and Reactivity of Carbon Materials 28

CONCLUSIONS AND RECOMMENDATIONS 37

$\begin{array}{ll}\text { ACKNOWLEDGMENTS } & 40\end{array}$

DISTRIBUTION LIST 


\section{LIST OF TABLES}

Table 1. LINEAR REGRESSION PARAMETERS OF THE EXPONENTIAL FITTING OF SORPTION DATA: CARBON DIOXIDE ON ACTIVATED COCONUT SHELL CHARCOAL.

Table 2. LINEAR REGRESSION PARAMETERS OF THE EXPONENTIAL FITTING OF SORPTION DATA: METHANE BY COCONUT SHELL CHARCOAL.

Table 3. MEASUREMENTS OR NITROGEN SORPTION CAPACITY BY ACTIVATED COCONUT SHELL CHARCOAL.

Table 4. PARAMETER VARIATIONS FOR CARBON DIOXIDE SORPTION BY ACTIVATED CARBON FIBER.

Table 5. PARAMETER VARIATIONS FOR METHANE SORPTION BY ACTIVATED CARBON FIBER 


\section{LIST OF FIGURES}

Figure 1._METHANE SORPTION BY ACTIVATED COCONUT SHELL CHARCOAL OVER NOTED TEMPERATURE RANGE.

Figure 2. SORPTION DATA PRESENTED WITH RESPECT TO THE POLYANI SORPTION POTENTIAL.

Figure 3. RECTILINEAR REPRESENTATION OF SORPTION ISOTHERMS OF CARBON DIOXIDE ON ACTIVATED COCONUT SHELL CHARCOAL $\quad 14$

Figure 4. CURVE FITTING PARAMETERS FOR THE SORPTION OF CARBON DIOXIDE OF ACTIVATED COCONUT SHELL CHARCOAL.

Figure 5. METHANE SORPTION BY ACTIVATED COCONUT SHELL CHARCOAL OVER NOTED TEMPERATURE RANGE.

Figure 6. RECTILINEAR PLOT OF DATA FOR METHANE SORPTION BY ACTIVATED COCONUT CHARCOAL

Figure 7. PARAMETER CORRELATION FOR METHANE SORPTION BY ACTIVATED COCONUT SHELL CHARCOAL.

Figure 8. ISOTHERM FOR SORPTION OF NITROGEN BY ACTIVATED NMP RESIDUE (A85) AT $77 \mathrm{~K}$.

Figure 9. SORPTION OF NITROGEN BY ACTIVATED NMP RESIDUE A85 AT $77 \mathrm{~K}$. 
Figure 10. ENERGETIC RELATIONSHIPS FOR THE INITIAL UPTAKE OF NITROGEN BY ACTIVATED NMP RESIDUE A85 AT $77 \mathrm{~K}$

Figure 11. RESOLUTION OF THE ISOTHERM FOR NITROGEN SORPTION BY ACTIVATED NMP.RESIDUE.

Figure 12. SORPTION OF CARBON DIOXIDE BY ACTIVATED CARBON FIBER.

Figure 13. EXPONENTIAL PLOT OF DATA FOR CARBON DIOXIDE SORPTION BY ACTIVATED CARBON FIBERS.

Figure 14. PARAMETER CORRELATION FOR CARBON DIOXIDE SORPTION BY ACTIVATED CARBON FIBER.

Figure 15. METHANE SORPTION BY ACTIVATED CARBON FIBER. $\quad 35$

Figure 16. ENERGETICS OF METHANE SORPTION BY ACTIVATED 36 CARBON FIBER

Figure 17. PARAMETER CORRELATION FOR METHANE SORPTION BY ACTIVATED CARBON FIBER 


\section{SUMMARY}

A one-year subcontract sponsored by the Carbon Materials Technology Group of the Oak Ridge National Laboratory (ORNL) with the Department of Geological Sciences, University of Tennessee, has been completed. A volumetric sorption system has been upgraded, in cooperation with commercial vendor, to allow the acquisition of data relevant to the program for the production of activated carbon molecular fiber sieves (ACFMS).

The equipment and experimental techniques have been developed to determine the pore structure and porosity of reference materials and materials produced at ORNL as part of the development of methods for the activation of carbon fibers by various etching agents. Commercial activated coconut shell charcoal (ACSC) has been studied to verify instrument performance and to develop methodology for deducing cause and effects in the activation processes and to better understand the industrial processes (gas separation, natural gas storage, etc.). Operating personnel have been trained, standard operating procedures have been established, and quality assurance procedures have been developed and put in place. Carbon dioxide and methane sorption have been measured over a temperature range 0 to $200 \mathrm{C}$ for both ACFMS and ACSC and similarities and differences related to the respective structures and mechanisms of interaction with the sorbed components. Nitrogen sorption (at $77 \mathrm{~K}$ ) has been used to evaluate "surface area" and "porosity" for comparison with the large data base that exists for other activated carbons and related materials.

The preliminary data base reveals that techniques and theories currently used to evaluate activated carbons may be somewhat erroneous and misleading. Alternate thermochemical and structural analyses have been developed that show promise in providing useful information related both to the activation process and to industrial applications of interest in the efficient and economical utilization of fossil fuels in a manner that is friendly to the earth's environment.

Research sponsored by the U.S. Department of Energy, Fossil Energy Advanced Research and Technology Materials Program, DOE/FE AA 1510 10 0, Work Breakdown Structure Element UT-3. 


\section{INTRODUCTION}

This program was geared to support the Fossil Energy Material Sciences Program with respect to several areas of interest in efficient production and utilization of energy. Carbon molecular sieves have great potential for economically purifying gases; i.e. removal of carbon dioxide from natural gas without having to resort to cryogenic techniques. Microporous carbons can be tailored to serve as adsorbents for natural gas in on-board storage in automotive applications, avoiding high pressures and heavy storage tanks. This program is a laboratory study to evaluate production methodologies and activation processes to produce porous carbons for specific applications. The Carbon Materials Technology Group of Oak Ridge National Laboratory (ORNL) is engaged in developmental programs to produce activated carbon fibers (ACF) for applications in fixed beds and/or flowing reactors engineering applications.

This subcontract with The University of Tennessee (UT) involved development of experimental techniques and theoretical evaluation of the results as a means of determining the kinetics and mechanisms of production and activation of carbonaceous materials at ORNL and other sites of members of the Carbon Products Consortium. Three specific topics were addressed:

\section{UT/ORNL PROJECT 1.01. Characterization of Coals and Coal Extracts: Samples of} West Virginia Coals and products upgraded by $\mathrm{N}$-methyl pyrolidone solvent extraction were characterized in terms of specific surface area and porosity. Additional samples were be provided by the Carbon Products Consortium as deemed appropriate by the technical monitor.

UT/ORNL PROJECT 1.02 Activation and Reactivity of Carbon Materials: Equipment and techniques were developed for the production of carbon molecular sieves and sorbents 
for storage of natural gas. Kinetic and chemical mechanisms were evaluated to aid in the development of production scale operations.

UT/ORNL PROJECT 1.03 Analyses of Pore Structures of Activated Carbons: Studies of carbon fibers and composite molecular sieves were evaluated for candidate materials - for energy related applications. All materials were characterized in terms of specific. surface area and porosity as a method of evaluating potential candidates for commercialpreparation programs.

The author was charged to evaluate equipment and methodologies to aid the existing program on site at ORNL. In addition staff members and technicians were trained to acquire data and to correlate the derived chemical and physical parameters with activated carbon development programs at ORNL. 


\section{EQUIPMENT AND EXPERIMENTS}

Existing Volumetric Sorption Apparatus: A computer controlled volumetric adsorption apparatus (Autosorb-1MP, Quantachrome Corporation, Boynton Beach, Florida) was available for use on the CMS program operating at cryogenic temperatures $\left(77^{\circ} \mathrm{K}\right.$ ). (The MP designation was for a modification to operate at lower pressures, ca. 0.1 torr, enabling the evaluation of microporosity, $<2 \mathrm{~nm}$ ). The adsorption isotherms of nitrogen were used for the evaluation of porosity and surface area as a means of evaluation of the efficacy of processes implemented at ORNL and other sites of the Carbon Products Consortium.

Upgrade of Volumetric Apparatus for Sorption Studies at Elevated Temperatures: The aforementioned apparatus was returned to the vendor for an upgrade to allow the measurement of the sorption of gases by candidate materials at elevated (noncryogenic) temperatures up to $1000^{\circ} \mathrm{C}$. This involved transport of the apparatus to the vendor's site, monitoring the structural changes, training to operate the instrument and existing computer software, and consultation related to additional changes to more comprehensively meet the needs of the ORNL/DOE program. This consumed one week of extensive effort on the part of the principal investigator and ORNL technician, M. R. Rogers. The vendor currently supplies a "Chemisorption" set of software, designed for the characterization of solid catalysts in terms of the sorption of gases or vapors at elevated temperatures. It is excellent methodology for the quantitative determination of the amount of various reactants held by the catalyst for varied pretreatments (i.e. oxidation, reduction, hydrogenation, etc.). We have been able to use the existing software to measure the uptake of gases of interest to the Fossil Energy Program (Carbon Dioxide, Methane, etc.) at temperatures up to and including $200^{\circ} \mathrm{C}$. The present system involves direct connection to sources for three (3) reactive gases, one sorbtive gas (nitrogen, oxygen, or argon) for physical adsorption analyses, and one inert gas (helium) for volumetric calibration purposes. Each of these sources is used on demand by the computer without human intervention to change gas supplies. 
Thermogravimetric Analyses with Mass Spectroscopic Support: A combined thermogravimetric analysis-mass spectroscopic (TGA-MS) method was used to determine the kinetics and mechanisms of changes wrought in the thermal and chemical processing of coal and coal-derived materials. The apparatus is composed of a computer-automated Mettler Thermoanalyzer (Model TA-1) combined with a UTI (Model 100C) quadrupole mass spectrometer for determining the composition of the input and output gases. (The interfaces, software, and analyses programs were developed for retrofitting to the existing balance system.) In this manner the quantitative mass loss measurement is evaluated in terms of the specific chemical reactions and physical alterations (desorption, pyrolysis, dehydration, etc.). These studies provide the details of the chemistry and physics involved in preparation (carbonization) and/or activation (chemical etching) on a laboratory scale to aid in forthcoming engineering scale experiments. An aliquot of each material was analyzed in three separate modes: 1) an aliquot of sample was heated (at a programmed constant rate of temperature rise) in pure helium ( 99.99 percent), to evaluate the temperature at which volatile components evolved in pyrolysis, 2) the residue of the previous helium pyrolysis was then oxidized over the same temperature range in an artificial air mixture comprised of $80 \%$ helium and $20 \%$ oxygen, to evaluate the oxidation of the pyrolysis residues, and 3) a fresh aliquot was subjected to oxidative pyrolysis using the same oxidizing gaseous medium as in (2). The last mode is used to evaluate the synergetic mechanisms that occur in simultaneous oxidation during pyrolysis. Sample mass changes and concentration of evolved gases are continuously monitored by a personal computer and a log of the data archived for subsequent analyses. Sample temperatures are monitored and controlled in a programmed mode to increase at $10^{\circ} \mathrm{C}$ per minute up to $1200^{\circ} \mathrm{C}$ with gas flow great enough to supply reaction gases and remove product gases at a rate such that the chemical reactions are rate controlling. Selected chemical (up to 12 with the current software) species are monitored in terms of the peak intensity of the appropriate ionic entity in the mass spectrometer. The balance system also provides a time differential of the mass loss that is informative and sensitive to changes occurring during the course of each diagnostic experiment. 
Thermogravimetric Analyses with Mass Spectroscopic Support: A combined thermogravimetric analysis-mass spectroscopic (TGA-MS) method was used to determine the kinetics and mechanisms of changes wrought in the thermal and chemical processing of coal and coal-derived materials. The apparatus is composed of a computer-automated Mettler Thermoanalyzer (Model TA-1) combined with a UTI (Model 100C) quadrupole mass spectrometer for determining the composition of the input and output gases. (The interfaces, software, and analyses programs were developed for retrofitting to the existing balance system.) In this manner the quantitative mass loss measurement is evaluated in terms of the specific chemical reactions and physical alterations (desorption, pyrolysis, dehydration, etc.). These studies provide the details of the chemistry and physics involved in preparation (carbonization) and/or activation (chemical etching) on a laboratory scale to aid in forthcoming engineering scale experiments. An aliquot of each material was analyzed in three separate modes: 1) an aliquot of sample was heated (at a programmed constant rate of temperature rise) in pure helium ( 99.99 percent), to evaluate the temperature at which volatile components evolved in pyrolysis, 2) the residue of the previous helium pyrolysis was then oxidized over the same temperature range in an artificial air mixture comprised of $80 \%$ helium and $20 \%$ oxygen, to evaluate the oxidation of the pyrolysis residues, and 3) a fresh aliquot was subjected to oxidative pyrolysis using the same oxidizing gaseous medium as in (2). The last mode is used to evaluate the synergetic mechanisms that occur in simultaneous oxidation during pyrolysis. Sample mass changes and concentration of evolved gases are continuously monitored by a personal computer and a log of the data archived for subsequent analyses. Sample temperatures are monitored and controlled in a programmed mode to increase at $10^{\circ} \mathrm{C}$ per minute up to $1200^{\circ} \mathrm{C}$ with gas flow great enough to supply reaction gases and remove product gases at a rate such that the chemical reactions are rate controlling. Selected chemical (up to 12 with the current software) species are monitored in terms of the peak intensity of the appropriate ionic entity in the mass spectrometer. The balance system also provides a time differential of the mass loss that is informative and sensitive to changes occurring during the course of each diagnostic experiment. 


\section{RESULTS AND DISCUSSION}

This program has 5 major thrusts; (1) to develop experimental methodology, (2) to evaluate the performance of the modified sorption apparatus (and accompanying computer software), (3) to correlate experimental results with theoretic models, (4) to provide meaningful data for development of industrial processes, and (5) to establish a data base for reference purposes. The following sections outline initial efforts based on three types. of activated carbons. Studies of methane and carbon dioxide sorption at temperatures . ranging from 0 to $200 \mathrm{C}$ aid in the evaluation of the capacity for an organic (hydrocarbon) and an inorganic (oxygenate) material of interest in separation and storage technology. Nitrogen sorption analyses, at $77 \mathrm{~K}$, are used to evaluate instrument performance and to supply information classically used to evaluate surface area and porosity.

\section{Analyses of Sorption of Commercial Activated Carbon:}

Activated coconut shell charcoal (ACSC) has been used in this program to evaluate the methodology of sorption studies for characterizing porous carbons prepared at ORNL. This material is known to have considerable merit for sorption applications in many fields. Such a data base will serve as a frame of reference for comparison purposes. A set of carbon dioxide sorption isotherms for temperatures from 0 to $200^{\circ} \mathrm{C}$ is shown in Figure 1, for pressures ranging from 0.1 to 760 torr. As expected there is an asymptotic uptake of carbon dioxide with increasing pressure, which is diminished as sample temperatures increase.

Isotherms of this type can be recast in terms of the sorption potential that is defined as:

$$
E(a)=-R T \ln \left(P / P_{\text {ref }}\right)
$$

or in dimensionless form:

$$
\mathrm{E}(\mathrm{a}) / \mathrm{RT}=-\ln \left(\mathrm{P} / \mathrm{P}_{\mathrm{ref}}\right)
$$

Consistent with standard states for thermodynamic properties, $\mathrm{P}$ is the pressure of the adsorptive, $\mathrm{CO}_{2}$, and $\mathrm{P}_{\text {ref }}$ is one atmosphere (760 torr). In accord with the Polyani 
concepts $\mathrm{E}(\mathrm{a})$ is the energy change associated with the change in pressure from the reference state to pressure corresponding to the given point on the isotherm. The amount of sorption of carbon dioxide is shown to be related to $E(a)$ as shown in Figure 2. The existence of the smooth, continuous curves of diminishing magnitude for each temperature indicates a singular common mechanism in play over the entire experimental range ( 0 to $\left.200^{\circ} \mathrm{C}\right)$.

For diagnostic purposes it is beneficial to linearize the curves in terms of the functional relation between the surface concentration and the sorption potential. The mathematical analyses aid in formulating a mechanistic model for the process and in supplying functional equations for process development. In this instance the amount of sorption, $\Gamma$ is functionally related to sorption potential and the amount bound at the standard pressure, $\Gamma_{\text {ref }}$ :

$$
\Gamma=\Gamma_{\text {ref }} e^{-\alpha E(a) R T}
$$

which is linearized in the logarithmic form:

$$
\ln \Gamma=\ln \Gamma_{\text {ref }}-\alpha E(\mathrm{a}) / \mathrm{RT}
$$

For diagnostic purposes the sorption isotherms are recast in Figure 3 and the data are indeed well linearized with the intercept equal to $\ln \Gamma_{\text {ref }}$ and the slope $\left.[d \Gamma / d E(a) / R T)\right]$ is seen to increase with increasing temperature. The merit of functional fit of the data to the theory is noted in the respective linear regression lines being excellent representations of the trends defined by the experimental data points. Numerical values are presented in Table 1 including the $R^{2}$ values as a measure of the excellence of fit (1.00 is a perfect fit). These same parameters are presented in Figure 4 for more graphic trend analyses. 


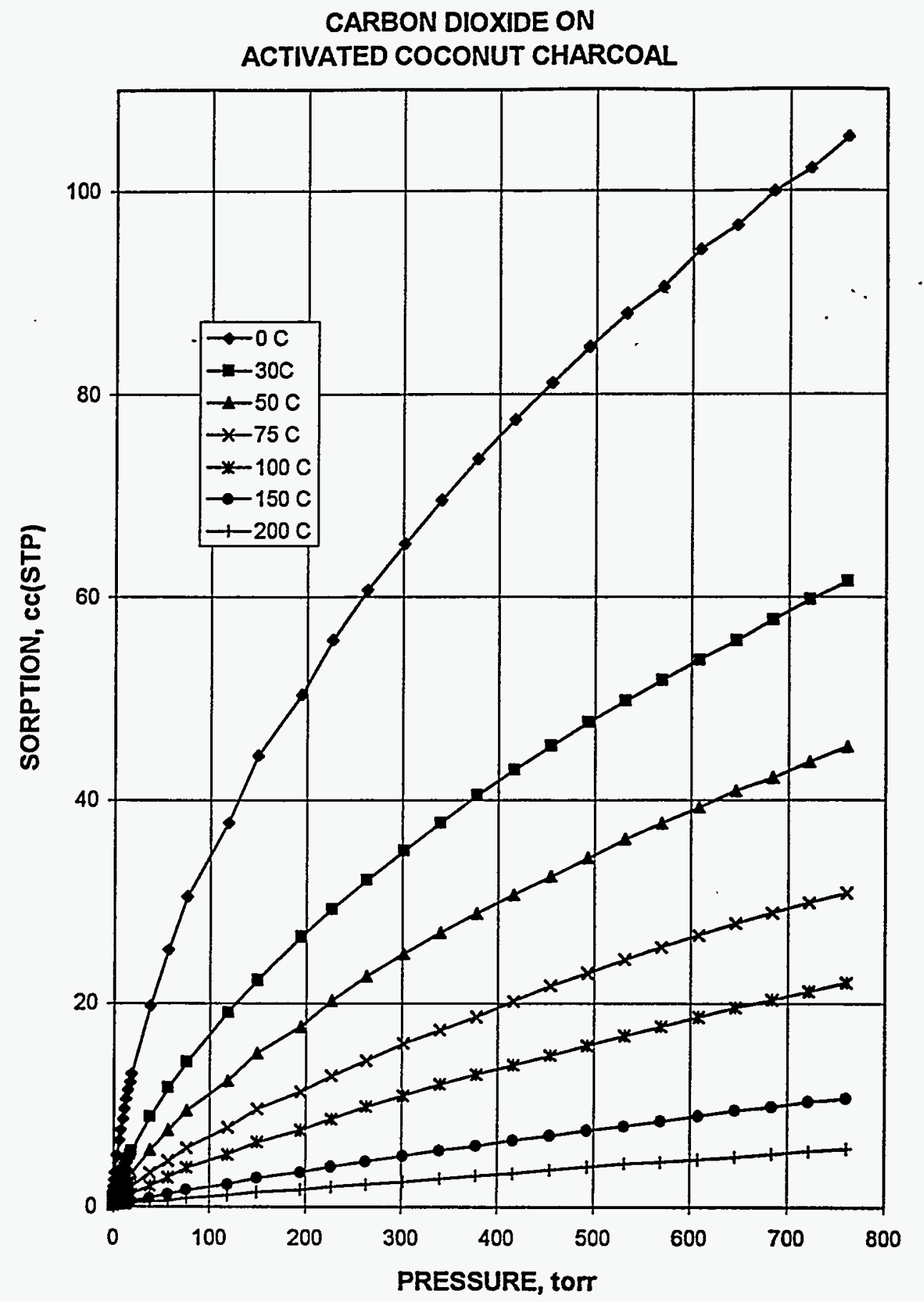

Figure 1. CARBON DIOXIDE UPTAKE BY ACTIVATED COCONUT SHELL CHARCOAL. Amount of sorption decreases at higher temperatures at any given pressure, indicating the amount of material involved in thermal swing operation. 


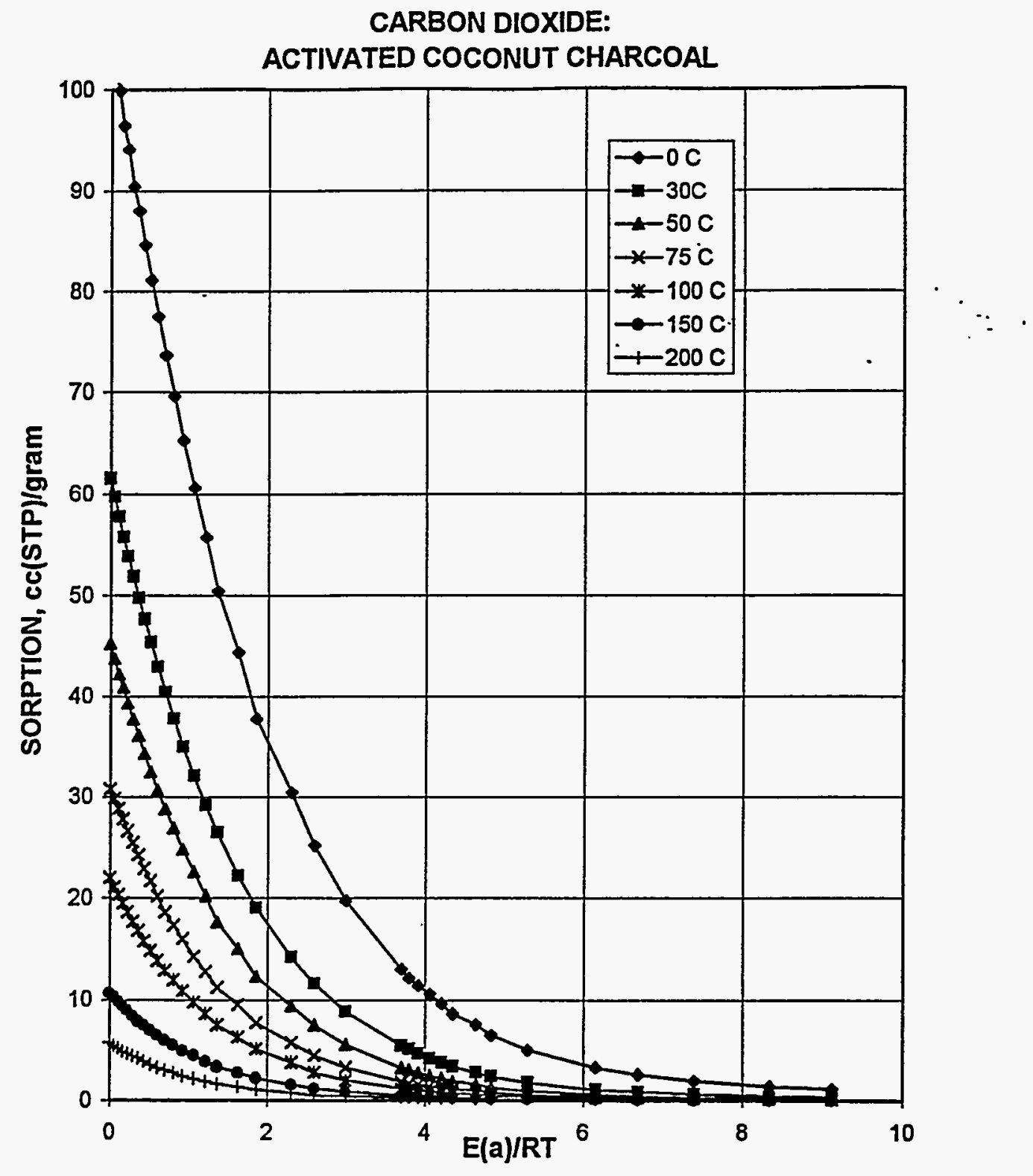

Figure 2. SORPTION DATA PRESENTED WITH RESPECT TO THE POLYANI SORPTION POTENTIAL. Smooth, continuous curves for each temperature indicate a singular common mechanism in play over the entire experimental range. 
CARBON DIOXIDE ON ACTIVATED COCONUT SHELL CHARCOAL

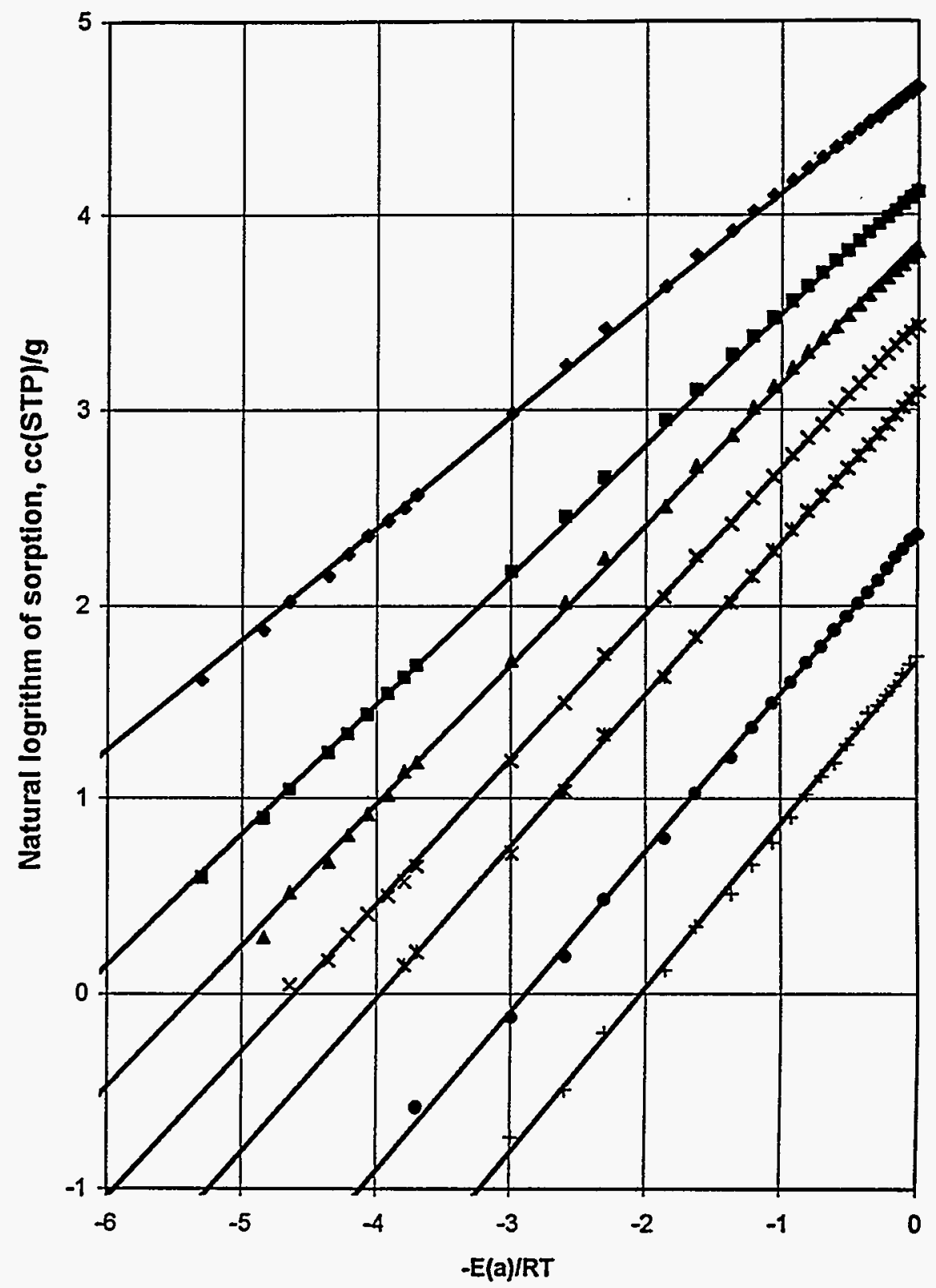

Figure 3. RECTILINEAR REPRESENTATION OF SORPTION ISOTHERMS OF CARBON DIOXIDE ON ACTIVATED COCONUT SHELL CHARCOAL. The linear regression lines are quite well fitted to the experimental data points. The sign change on . E(a) is used to correlate with the data of Figure 1 (monatonic increases of sorption). 


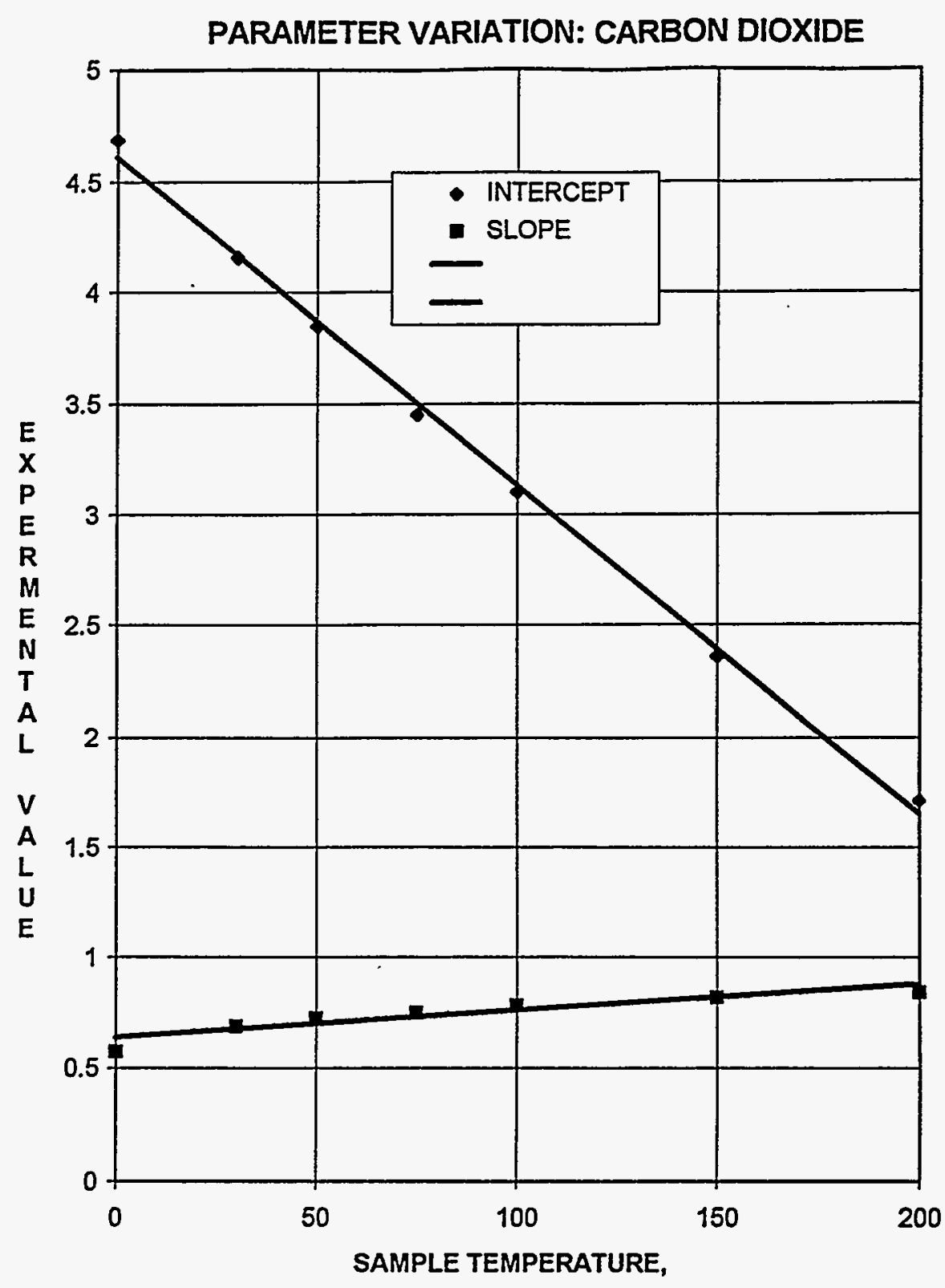

Figure 4. CURVE FITTING PARAMETERS FOR THE SORPTION OF CARBON DIOXIDE OF ACTIVATED COCONUT SHELL CHARCOAL. The intercept shows marked dependence on temperature compared to the much lesser dependence of the slope values. $R^{2}$ is virtually independent of temperature consistent with a singular mechanism. 
Table 1. LINEAR REGRESSION PARAMETERS OF THE EXPONENTIAL FITTING OF SORPTION DATA: CARBON DIOXIDE BY ACTIVATED COCONUT SHELL CHARCOAL.

$\begin{array}{cccc}\begin{array}{c}\text { Temperature } \\ { }^{\circ} \mathrm{C}\end{array} & \text { Intercept } & \text { Slope } & \text { R-squared } \\ 0 & \ln \left(\Gamma_{\text {ref }}\right) & \mathrm{d} \ln \Gamma / \mathrm{d}[\mathrm{E}(\mathrm{a}) / \mathrm{RT}] & . \\ 30 & 4.688 & 0.5732 & 0.9995 . \\ 50 & 4.158 & 0.6680 & 0.9996 \\ 75 & 3.853 & 0.7216 & 0.9994 \\ 100 & 3.451 & 0.7493 & 0.9997 \\ 150 & 3.102 & 0.7833 & .09997 \\ 200 & 2.362 & 0.8194 & 0.9990 \\ & 1.713 & 0.8420 & 0.9983\end{array}$

The relevant parameters describing the sorption of carbon dioxide by the activated coconut shell charcoal can be expressed quite accurately by the following:

$$
\begin{aligned}
& \text { Intercept }=\ln \left(\Gamma_{\text {ref }}\right)=4.612-0.0148 \mathrm{t} \\
& \text { Slope }=d \ln \Gamma / d[E(a) / R T]=0.6355+0.0013 \mathrm{t} .
\end{aligned}
$$

Similar treatment of the data for methane sorption on the activated coconut shell charcoal was used to evaluate the related parameters as shown in Table 2 (based on data of Figures 5, 6, and 7). Correspondingly the parameters for methane are:

$$
\begin{aligned}
& \text { Intercept }=\ln \left(\Gamma_{\text {ref }}\right)=3.8826-0.0154 t \\
& \text { Slope }=d \ln \Gamma / d[E(a) / R T]=0.883+0.0008 t
\end{aligned}
$$


Table 2. LINEAR REGRESSION PARAMETERS OF THE EXPONENTIAL FITTING OF SORPTION DATA: METHANE BY COCONUT SHELL CHARCOAL.

\begin{tabular}{|c|c|c|c|}
\hline Temperature & Intercept & Slope & R-squared \\
\hline${ }^{\circ} \mathrm{C}$ & $\ln \left(\Gamma_{\mathrm{ref}}\right)$ & $\mathrm{d} \ln \Gamma / \mathrm{d}[\mathrm{E}(\mathrm{a}) / \mathrm{RT}]$ & \\
\hline 0 & 3.945 & 0.8346 & 0.9967 \\
\hline 30 & 3.394 & 0.8764 & 0.9991 \\
\hline 50 & 3.074 & 0.9006 & 0.9991 \\
\hline 75 & 2.708 & 0.9369 & 0.9993 \\
\hline 100 & 2.328 & 0.9486 & .09995 \\
\hline 150 & 1.613 & 0.9678 & 0.9996 \\
\hline
\end{tabular}




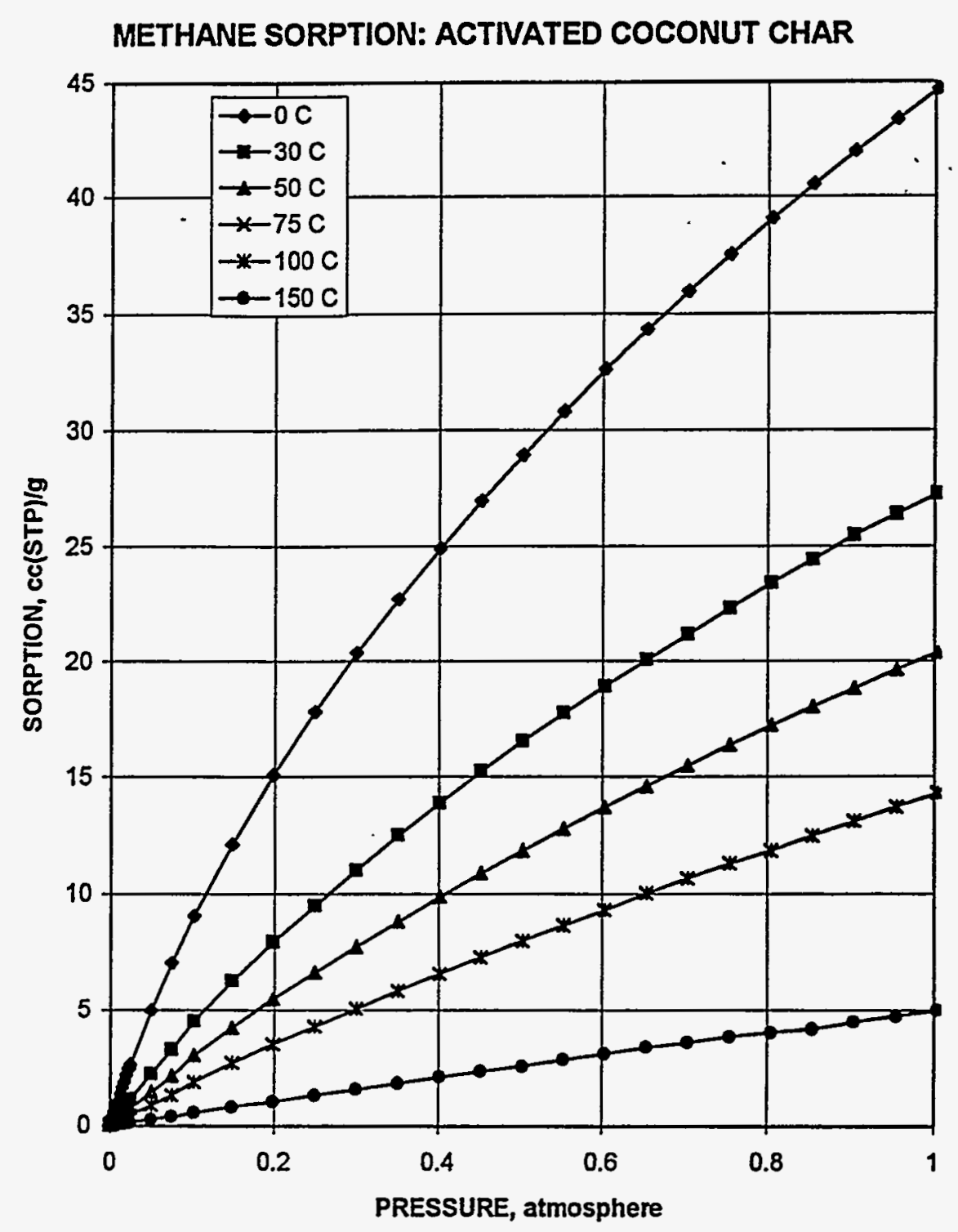

Figure 5. METHANE SORPTION BY ACTIVATED COCONUT SHELL CHARCOAL OVER NOTED TEMPERATURE RANGE. Pressures reduced to standard atmosphere (760 torr).. 


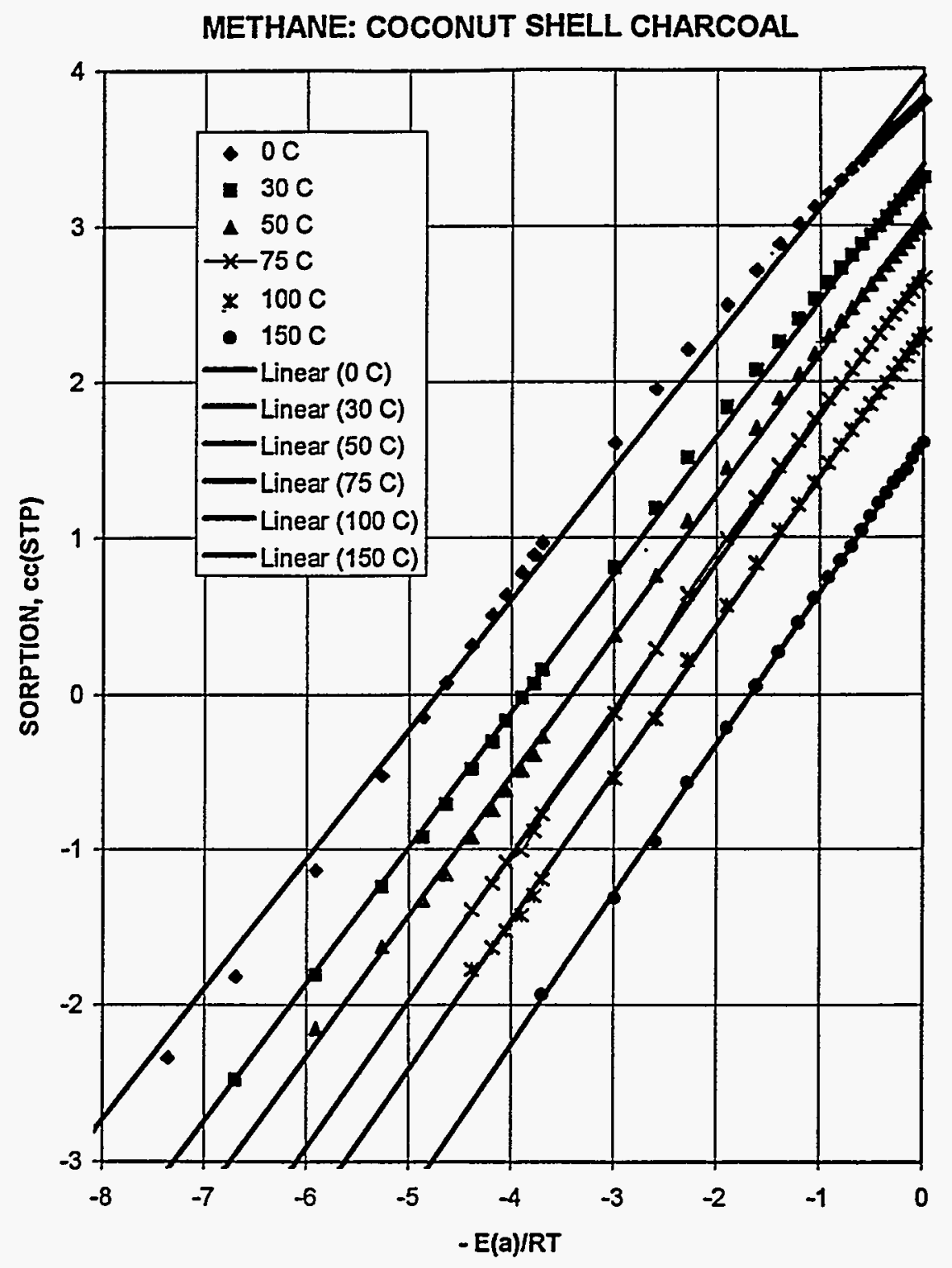

Figure 6. RECTIINEAR PLOT OF NATURAL LOGARITHM FOR METHANE SORPTION BY ACTIVATED COCONUT CHARCOAL. 
METHANE SORPTION PARAMETERS: ACTIVATED COCONUT CHARCOAL

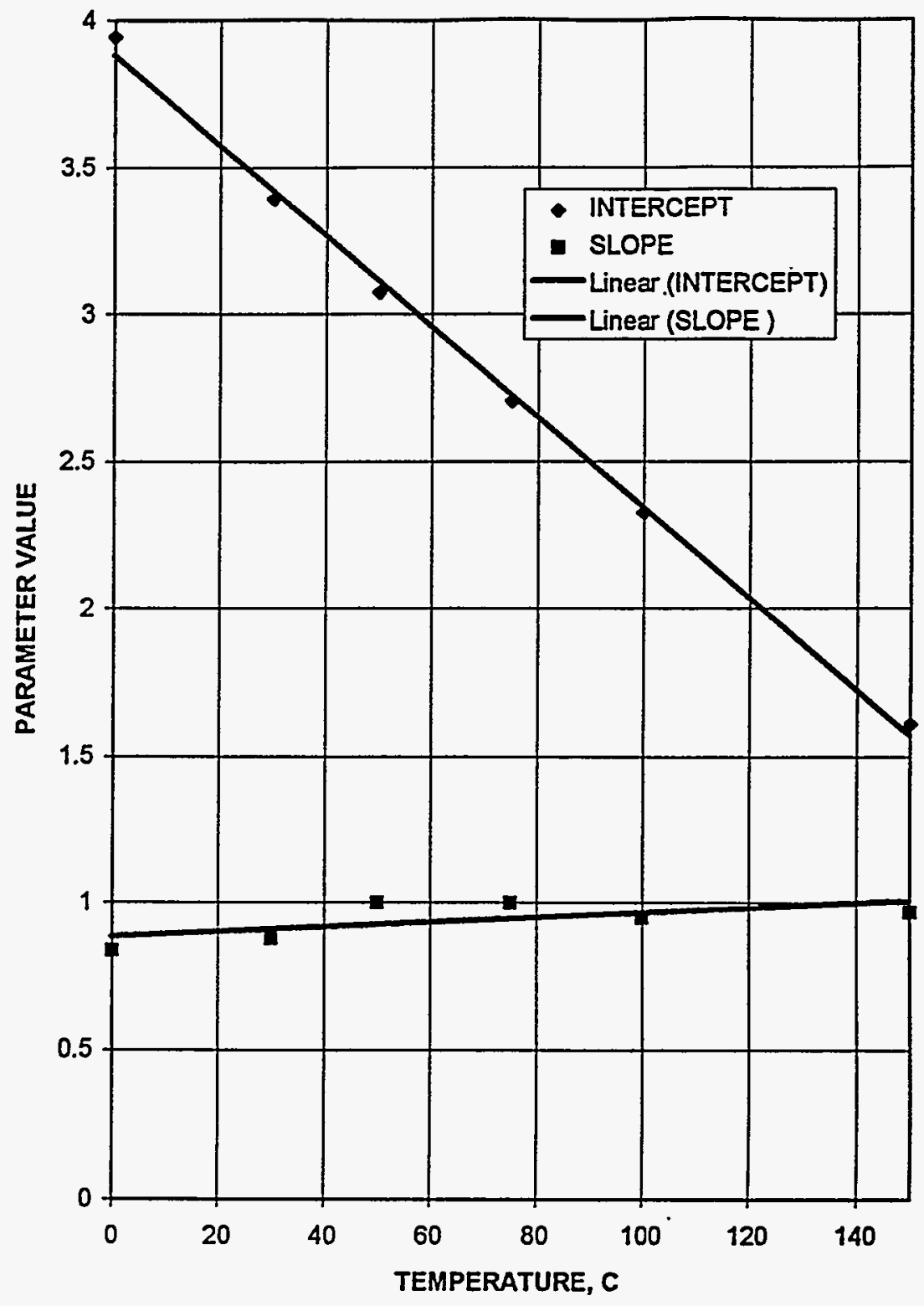

Figure 7. PARAMETER CORRELATION FOR METHANE SORPTION BY ACTIVATED COCONUT SHELL CHARCOAL. 
Characterization of Coals and Coal Extracts: The University of West Virginia program to find non-fuel uses for the indigenous vast reserves of marginal coal has involved upgrading by solvent extraction/refining to make premium materials. The UCAR Carbon Company evaluates the products in terms of the potential of a marketable material. ORNL has used their equipment and expertise to characterize materials that show promise. To this end two samples were steam activated at UCAR. Sample A-67 was a residue from NMP : . extraction of hydrotreated coal and sample U-85 was a residue from NMP extraction of untreated coal. These were treated in water/nitrogen at $900{ }^{\circ} \mathrm{C}$ to $64 \%$ and $86 \%$ burnoff, respectively. Sorption isotherms akin to that of Figure 8 have been acquired and analyzed by classical BET methodology and the results are presented in Table 3 .

\section{Table 3. MEASUREMENTS OR NITROGEN SORPTION CAPACITY BY} ACTIVATED N-METHYLPYROLIDONE EXTRACT RESIDUES..

$\begin{array}{llrlc} & \text { A-85 } & \text { A-67 } & & \text { RATIO } \\ \text { 5 POINT BET AREA } & 770 & 212 & \mathrm{~m}^{2} / \mathrm{gm} & 3.63 \\ \text { LANGMUIR AREA } & 1672 & 510 & \mathrm{~m}^{2} / \mathrm{gm} & 3.27 \\ \text { MICROPORE AREA } & 422 & 132 & \mathrm{~m}^{2} / \mathrm{gm} & 3.20 \\ \text { t-METHOD AREA } & 347 & 80.4 & \mathrm{~m}^{2} / \mathrm{gm} & 4.31 \\ \text { DR METHOD AREA } & 964 & 477 & \mathrm{~m}^{2} / \mathrm{gm} & 2.02 \\ \text { CUMULATIVE AREA } & 248 & 81.1 & \mathrm{~m}^{2} / \mathrm{gm} & 3.06 \\ \text { t-METHOD MICROPORE VOLUME } & 0.984 & 0.224 & \mathrm{~cm}^{3} / \mathrm{gm} & 4.39\end{array}$

These results are based upon the application of adsorption theories that are based on models derived for adsorption on the surface of a rigid, noninteracting solid surface. These materials do not meet the criteria for use of such a model. However, it has become customary to quote these values since the equations and models have been blindly applied. One is nearly forced to continue to quote the sorption capacity in terms of a "surface area equivalent" so that first order comparisons can be made to the literature values. A detailed standard practice procedure is warranted to aid in communications. 


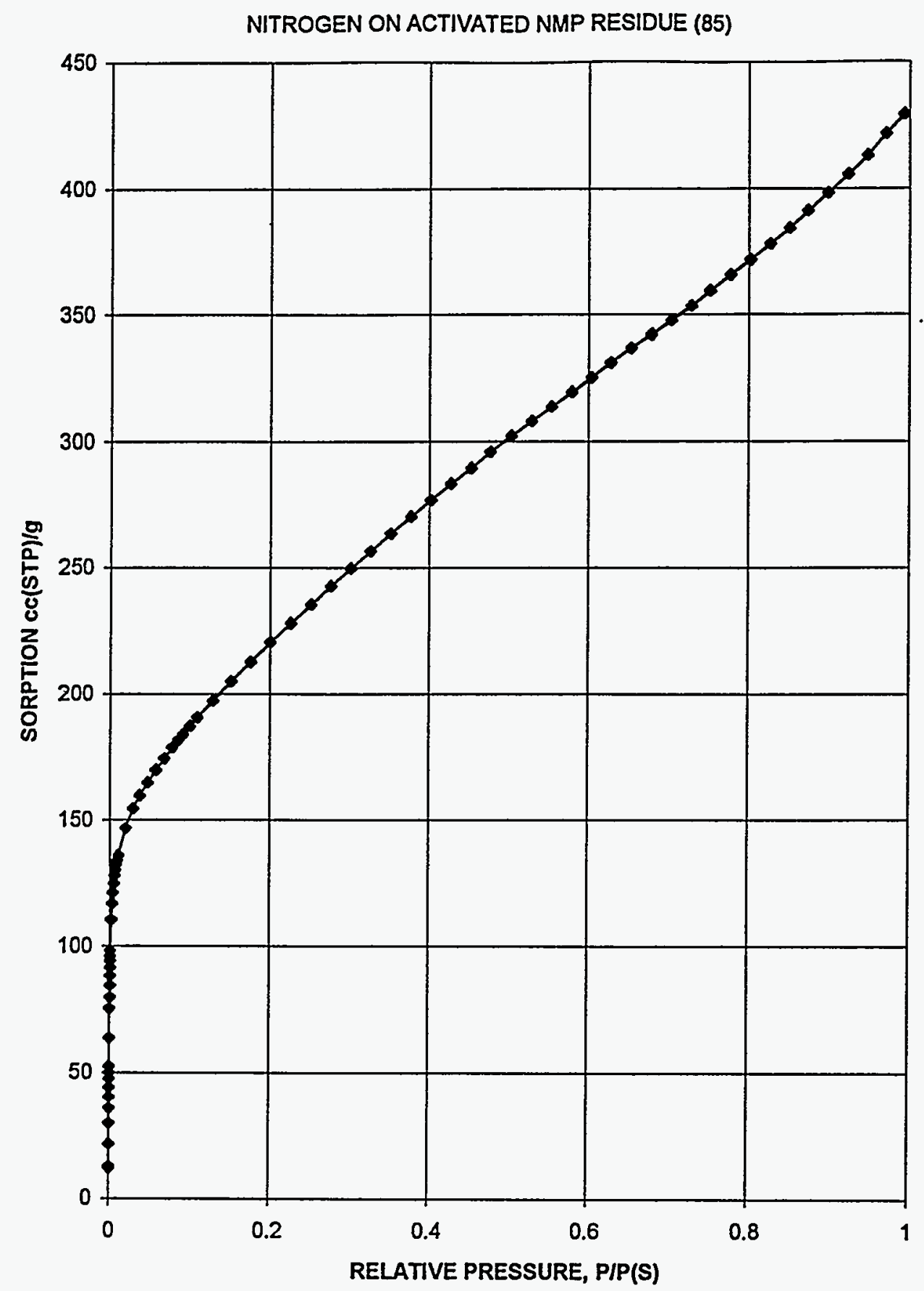

Figure 8. ISOTHERM FOR SORPTION OF NITROGEN BY ACTIVATED NMP RESIDUE (A85) AT $77 \mathrm{~K}$. Note the sigmoidal shape attributable to multilayer formation on the external surfaces. 
Notwithstanding, the results show several pertinent facts:

1. There is considerable amount of mesoporosity generated in the activation process. This would indicate that this material may be promising as a catalyst support.

2. The orifice dimension of the mesopores is equal to or greater than their internal dimensions. Otherwise there would be hysteresis in the desorption isotherm in the range 0.5 to $1.0 \mathrm{P}(\mathrm{S})$.

3. There is appreciable microporosity present that may be of merit in molecular sieve applications.

4. The sorption capacity is quite good since the $770 \mathrm{~m}^{2} / \mathrm{gm}$ value compares quite well with commercial activated carbons.

Additional information is obtained by more detailed analyses of the isotherm. The sigmoidal shaped curve of Figure 8 is grossly distorted from the Type II classification, in that the "knee" at ca. $0.1 \mathrm{P} / \mathrm{P}(\mathrm{S})$ is quite large on a relative basis. Furthermore, the major portion of the sorption occurs at very low pressures and is not readily evaluated when plotted as a direct function of pressure. The "characteristic curve" methodology can be used to expand the data significantly as shown in Figure 9, where the uptake at low pressure (high energy) portion of the data can be evaluated with respect to the adsorption per se that occurs at higher pressures. The linear variation of sorption with energy is quite apparent up to ca. $160 \mathrm{cc}(\mathrm{STP}) / \mathrm{g}$ where the multilayer formation and capillary condensation is seen as an enhancement factor. This deviation begins at ca. $0.05 \mathrm{P}(\mathrm{S})$ where physical adsorption commences to a sensible degree. To permit a more informative view of the situation, the coordinate system can be changed into the format of Figure 10 where one can readily note the finite energy of sorption at very low uptake, "zero coverage." This is commensurate with the first sorbed molecule having a finite sorption energy of $1.90 \mathrm{kcal} / \mathrm{mole}(7.96 \mathrm{~kJ} / \mathrm{mole})$. Thus it exists with a finite vapor pressure of $4.00 \times 10^{-6}$ atmospheres ( $3.04 \times 10^{-3}$ torr), and a linear variation with uptake is very evident and seems to define the experimental trends very well. 
NITROGEN SORPTION BY ACTIVATED NMP RESIDUE: A85 at 77K

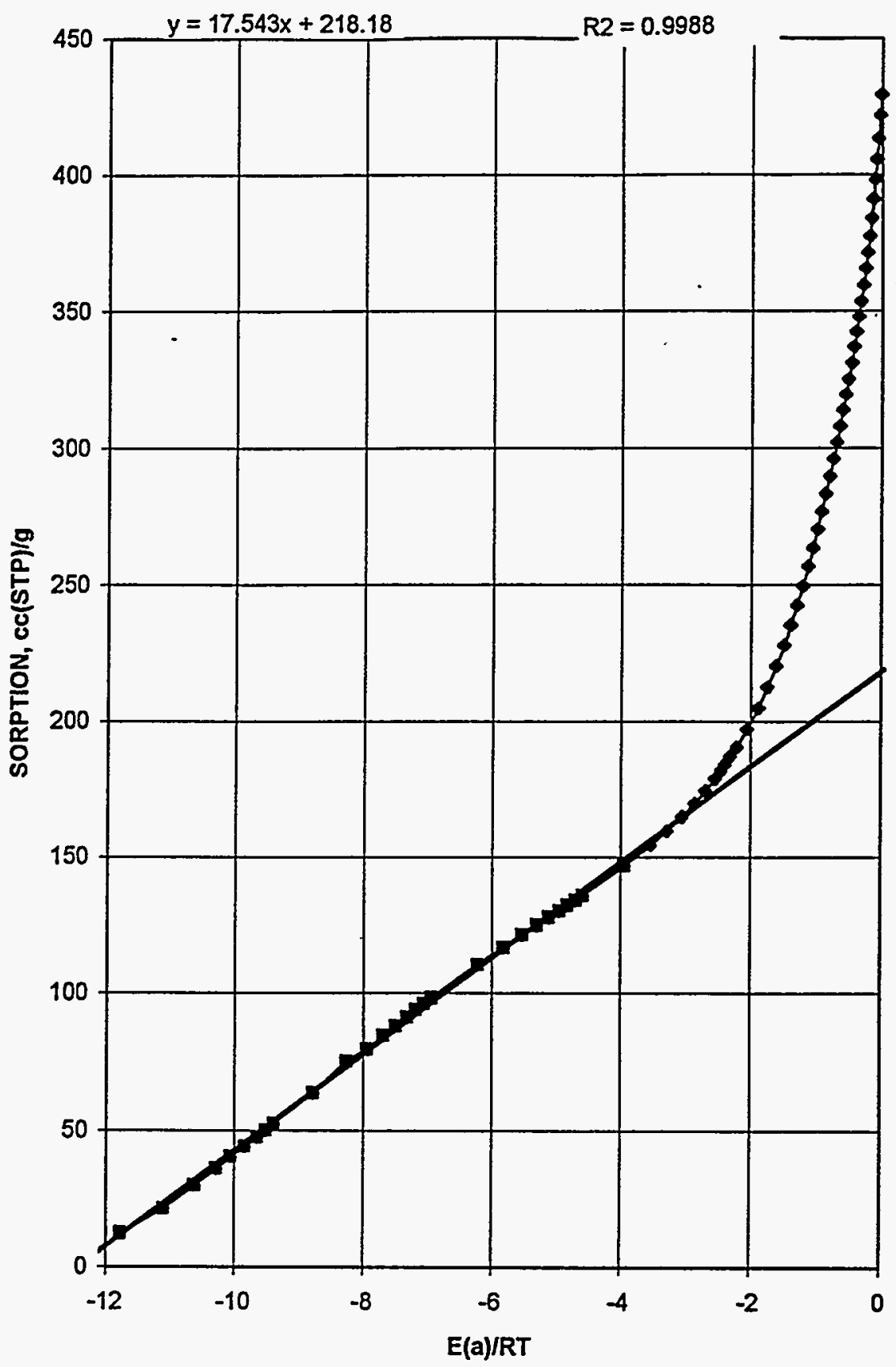

Figure 9. SORPTION OF NITROGEN BY ACTIVATED NMP RESIDUE A85 AT 77 $\mathrm{K}$. Linear variation of sorption noted over extended range. 


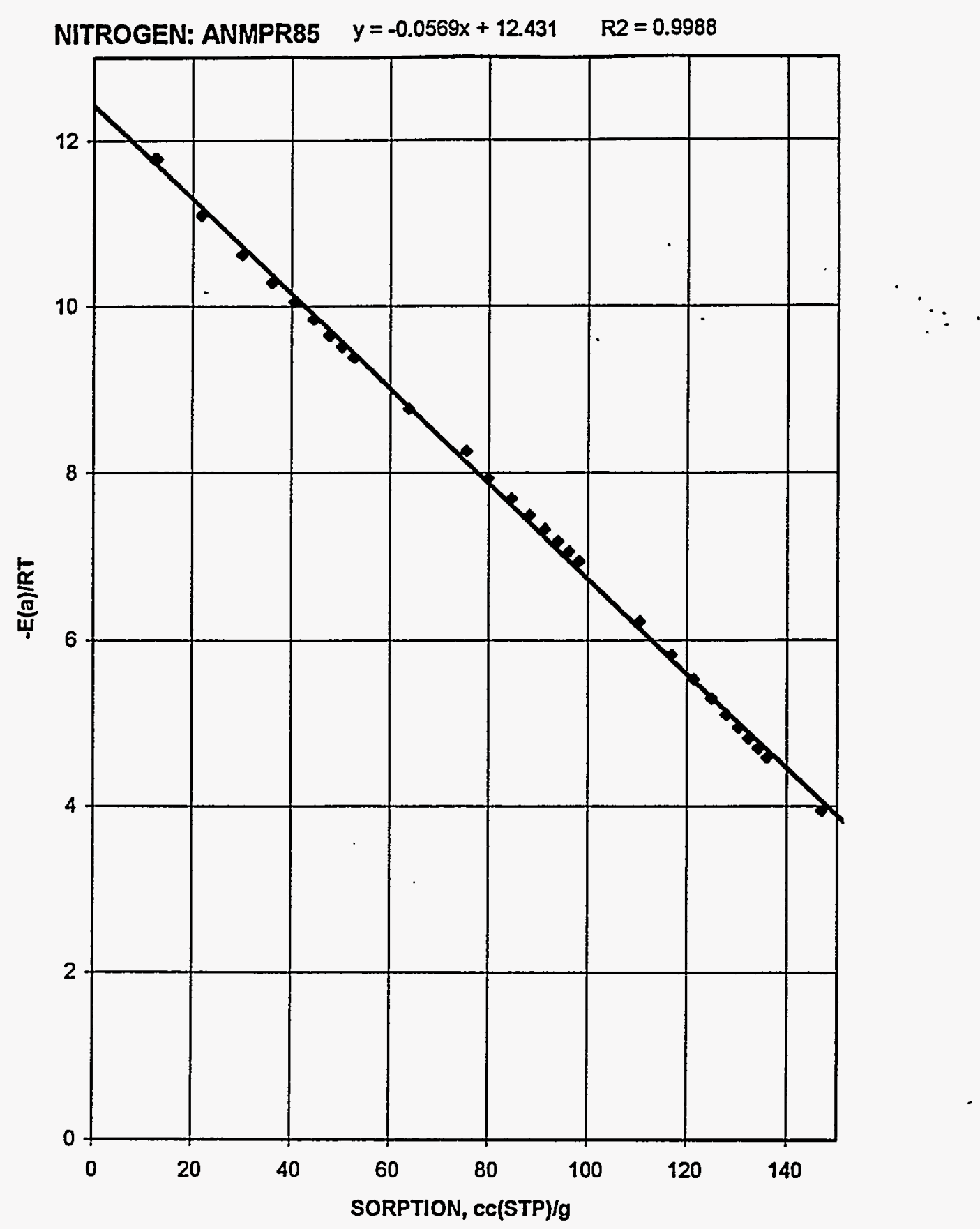

Figure 10. ENERGETIC RELATIONSHIPS FOR THE INITIAL UPTAKE OF NITROGEN BY ACTIVATED NMP RESIDUE A85 AT $77 \mathrm{~K}$. Coordinate system changed to emphasize the energetics as dependent variable. 
The energetic behavior from the linear range of Figure 9,

$$
\Gamma \text { (bound })=218.2+17.54 \mathrm{E}(\mathrm{a}) / \mathrm{RT} \text {, }
$$

can be used to extrapolate over the entire pressure range and the calculated numerical values subtracted from the experimental values at each pressure. The results, presented in Figure 11 show that the residual physical sorption is linear with pressure as per weak process following the classical Henry's law (linear variation with pressure):

$$
\Gamma(\text { physical })=210.59 *[\mathrm{P} / \mathrm{P}(\mathrm{S})-0.0521]
$$

This leaves a small residual component of adsorption above ca.90 $\mathrm{P}(\mathrm{S})$ that is undoubtedly due to the interparticulate condensation between the charcoal particles. The problem of evaluating a pore size distribution, if one exists, is yet to be addressed for this material. 


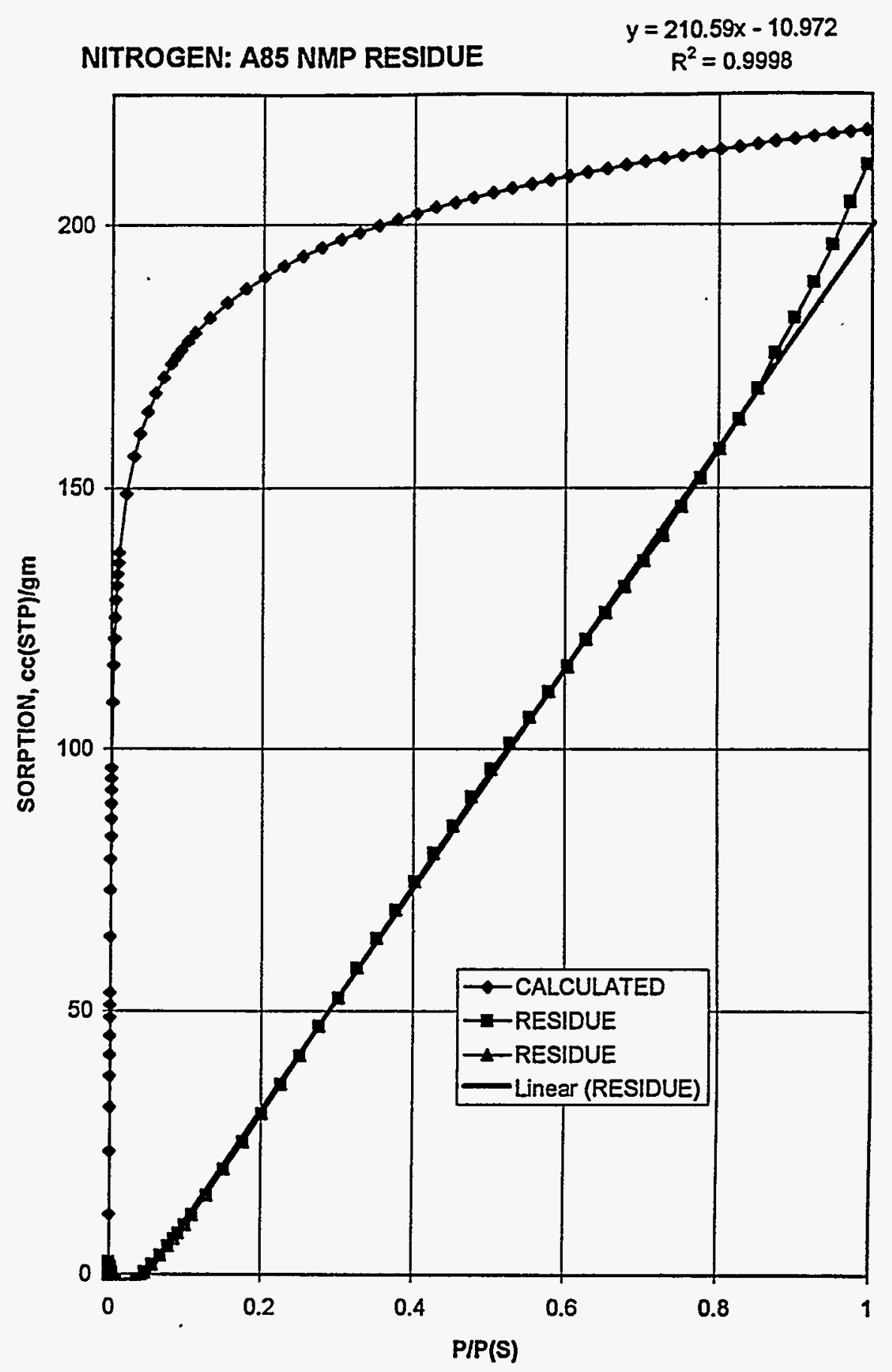

Figure 11. RESOLUTION OF THE ISOTHERM FOR NITROGEN SORPTION BY ACTIVATED NMP RESIDUE. Constant (coverage independent) sorption energy is implied from the Henry's law uptake (linear sorption with respect to pressure). 
Activation and Reactivity of Carbon Materials.

Carbon fibers have been activated in the ORNL program to develop the technology and data base required to efficiently produce activated carbon fiber molecular sieves (ACFMS) tailored for particular applications. To this end carbon fibers have been activated in water/nitrogen mixtures at various temperatures and duration. An initial study of carbon . dioxide sorption by one of the products is presented in Figure 12. An initial cursory examination indicates similarity to that of ACSC (Figure 1). The mechanistic differences are difficult to discern in this coordinate system. For comparative purposes the data can be cast in the format of the exponential relationship that has served well to produce a rectilinear form for the activated coconut shell charcoal (Figure 3) as noted in Figure 13 It is quite obvious that a linear relationship does not prevail for ACFMS. To systematically measure the trends, a second order least squares polynomial fit was employed to the data, yielding satisfactory approximations to the experimental results. The parameters are given in Table 4 for the mathematical relationship:

$$
\ln \Gamma=\ln \Gamma(\mathrm{ref})+\mathrm{a} E(\mathrm{a}) / \mathrm{RT}-\mathrm{b}[\mathrm{E}(\mathrm{a}) / \mathrm{RT}]^{2}
$$

Qualitatively, the trends are similar to that of the ACSC in that the intercept decreases with increasing temperature and the first derivative, a, increases with temperature. The second order term, $b$, is probably a reflection of the more rigid structure of the ACFMS fiber skeleton that does not exist in the activated granules of ACSC. Alternately the enhanced rigidity may be due to the more extensive graphitization of the ORNL carbon fibers subsequent to activation. The variations of the curve fitting parameters are more readily visualized in the graphical format of Figure 14, and the regression correlations are noted as the lines approximating the data points. For comparison purposes, the following 
CARBON DIOXIDE; ACF 21-11

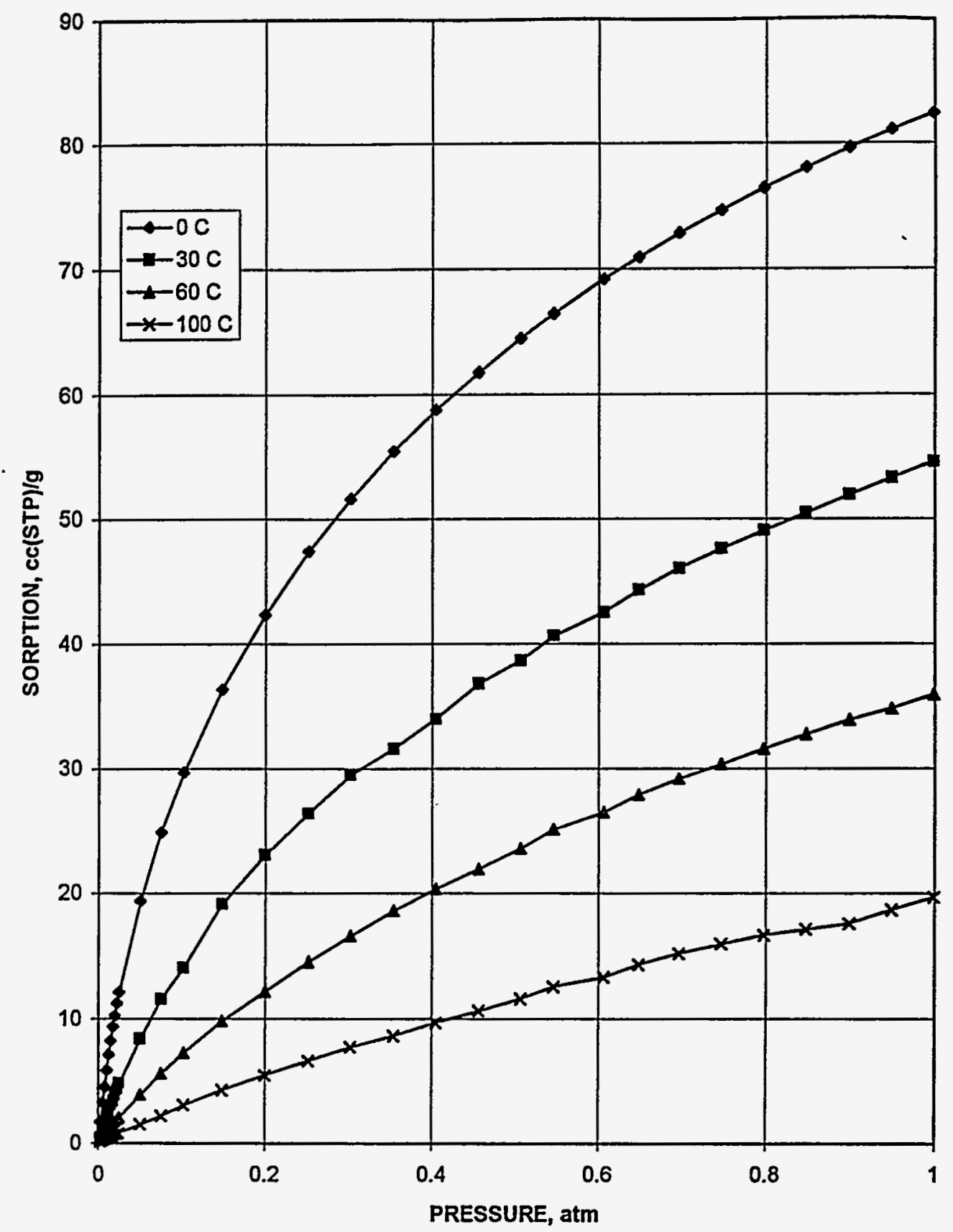

Figure 12. SORPTION OF CARBON DIOXIDE BY ACTIVATED CARBON FIBER. Monatonic increase of activity with increasing pressure is asymptotically diminished at increasing temperature. 
CARBON DIOXIDE: ACF21-11

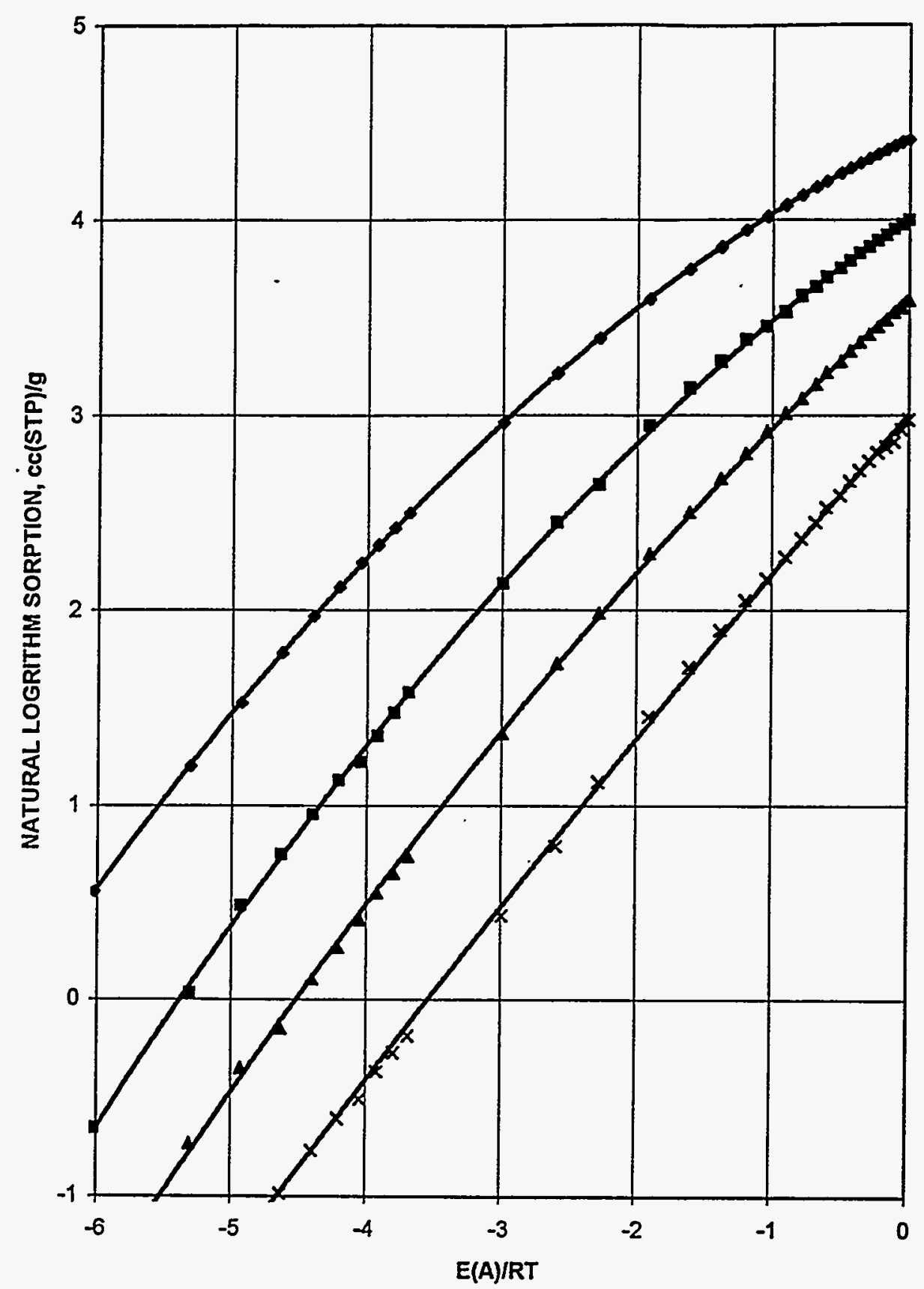

Figure 13. EXPONENTIAL PLOT OF DATA FOR CARBON DIOXIDE SORPTION BY ACTIVATED CARBON FIBERS. Second order regression fit to the data shown as lines fitted to the experimental data points. 
functionality is derived from the regression analyses for the sorption of carbon dioxide by ACFMS:

$$
\ln \Gamma(\mathrm{ref})=4.425-0.0141 \mathrm{t}
$$

and

$$
\mathrm{d} \ln \Gamma / \mathrm{d}[\mathrm{E}(\mathrm{a}) / \mathrm{RT}]=0.3200+0.00489 \mathrm{t} .
$$

The second order term appears to reach a maximum, constant, value around $30 \mathrm{C}$ as sample temperatures are decreased, indicating that a saturation value is achieved, commensurate with a flexing structure, expanding to a limited volume of a rigid skeletal structure. At temperatures somewhat above our experimental range this term will become insignificant. Further work is warranted to verify this phenomenon and to deduce mechanistic and structural information related to the fundamental understanding of ACFMS and its most efficient use in commercial applications.

Table 4. PARAMETER VARIATIONS FOR CARBON DIOXIDE SORPTION BY ACTIVATED CARBON FIBER.

$\begin{array}{lllll}\text { Temperature } & \ln \Gamma(\text { ref }) & \mathrm{a} & \mathrm{b} & \mathrm{R}^{2} \\ 0 \mathrm{C} & 4.413 & 0.3279 & 0.0520 & 1.0000 \\ 30 \mathrm{C} & 4.005 & 0 . .4721 & 0.0506 & 0.9998 \\ 60 \mathrm{C} & 3.606 & 0 . .6369 & 0.0357 & 0.9997 \\ 100 \mathrm{C} & 3.003 & 0 . .8217 & 0.0102 & 0.9994\end{array}$


PARMETERS: CARBON DIOXIDE BY ACFMS

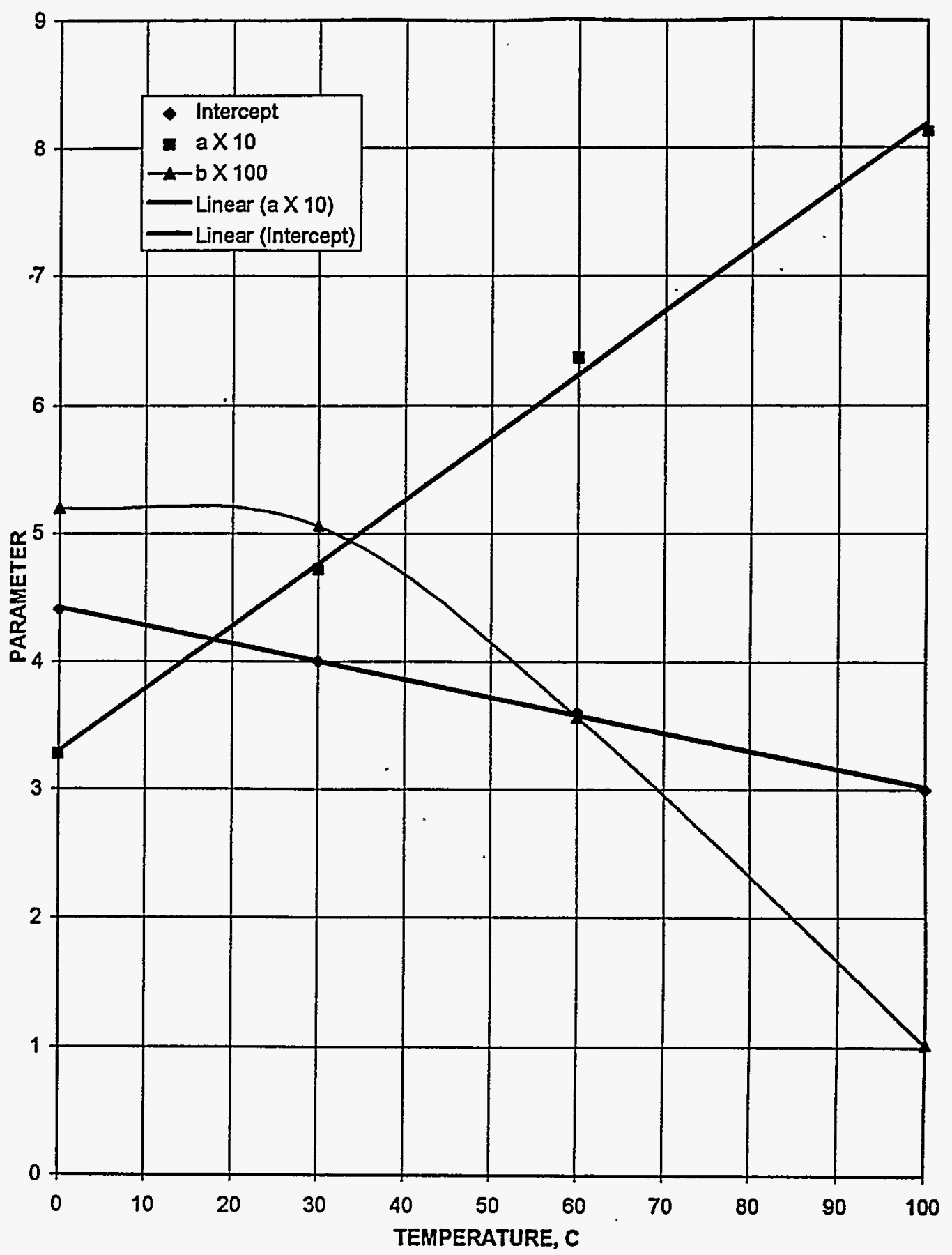

Figure 14. PARAMETER CORRELATION FOR CARBON DIOXIDE SORPTION BY ACTIVATED CARBON FIBER. Intercept and first order term vary linearly with temperature (regression lines). Second order term constant at lower temperatures (< ca. 30C). 
Similar data was obtained for sorption of methane by the same sample of activated carbon fiber, and the results are shown in Figures 15,16, and 17. The curve fitting process is somewhat less precise as reflected in the correlation of the regression lines to the data (shown in Figure 17).

\section{Table 5. PARAMETER VARIATIONS FOR METHANE SORPTION BY} ACTIVATED CARBON FIBER.

$\begin{array}{lllll}\text { Temperature } & \ln \Gamma(\mathrm{ref}) & \mathrm{a} & \mathrm{b} & \mathrm{R}^{2} \\ 0 \mathrm{C} & 3.747 & 0.4673 & 0.0508 & 1.0000 \\ 30 \mathrm{C} & 3.328 & 0.6157 & 0.0433 & 0.9998 \\ 60 \mathrm{C} & 2.962 & 0.7568 & 0.0257 & 0.9997 \\ 100 \mathrm{C} & 2.355 & 0.8820 & 0.0073 & 0.9994\end{array}$

For further comparison, the following mathematical relationships exist from the regression analyses for the sorption of methane by ACFMS:

$$
\ln \Gamma(\mathrm{ref})=3.754-0.0138 \mathrm{t}
$$

and

$$
\mathrm{d} \ln \Gamma / \mathrm{d}[\mathrm{E}(\mathrm{a}) / \mathrm{RT}]=0.4868+0.00397 \mathrm{t}
$$

The second order term does not appear to reach a maximum plateau, but monotonically decreases to a value rapidly approaching insignificant contribution at higher temperatures. The uptake of methane is not great enough here to attain the saturation value corresponding to the saturation effect of filling the finite pore space of this ACFMS. Further work is warranted (at both higher and lower isotherm temperatures) to verify these phenomenon and to deduce mechanistic and structural information related to the fundamental understanding of ACFMS and its most efficient use in commercial applications. The volume limitations have not been reached by the uptake of methane in this temperature range as witnessed in the continued near linear increase of the second order term with decreased temperature. This interpretation can well be bolstered (or discredited) by additional sorption analyses at lower $(<0 \mathrm{C})$ isotherm temperatures. 
METHANE SORPTION BY ACTIVATED CARBON FIBER

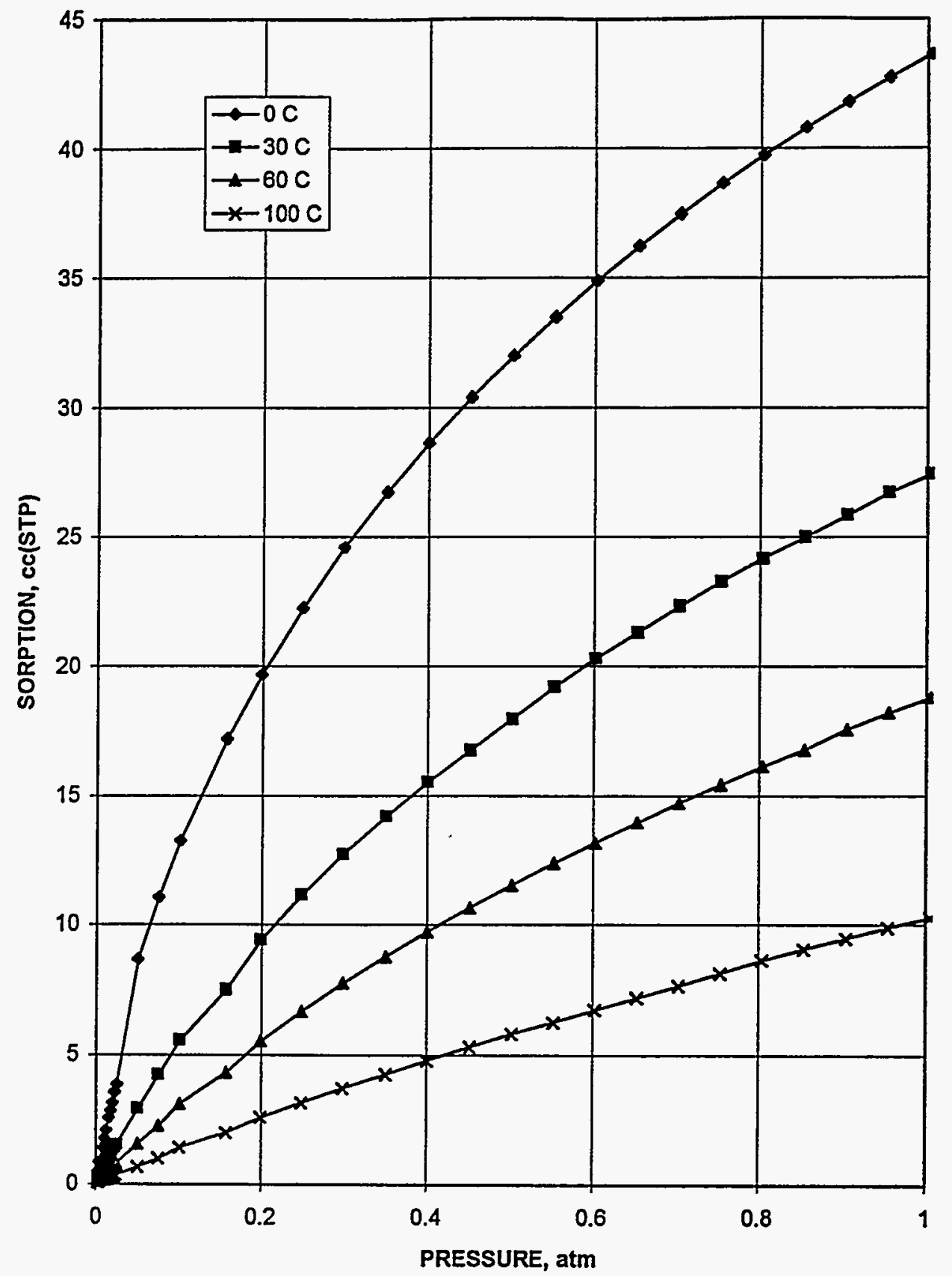

Figure 15. METHANE SORPTION BY ACTIVATED CARBON FIBER. Sorption trends resemble those of other gases at first glance. 


\section{METHANE: ACFMS}

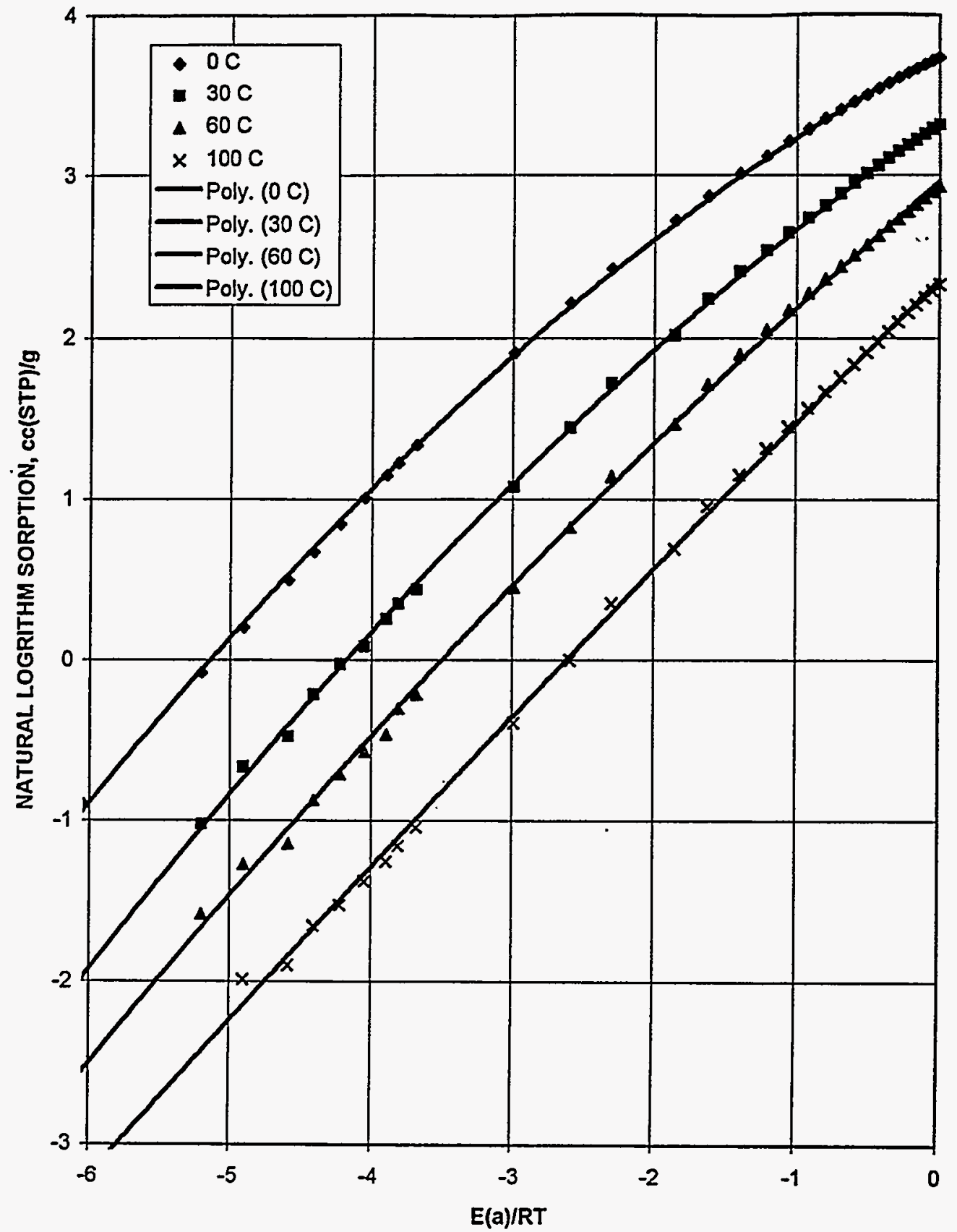

Figure 16. ENERGETICS OF METHANE SORPTION BY ACTIVATED CARBON FIBER. 
SORPTION PARAMETERS 21-11

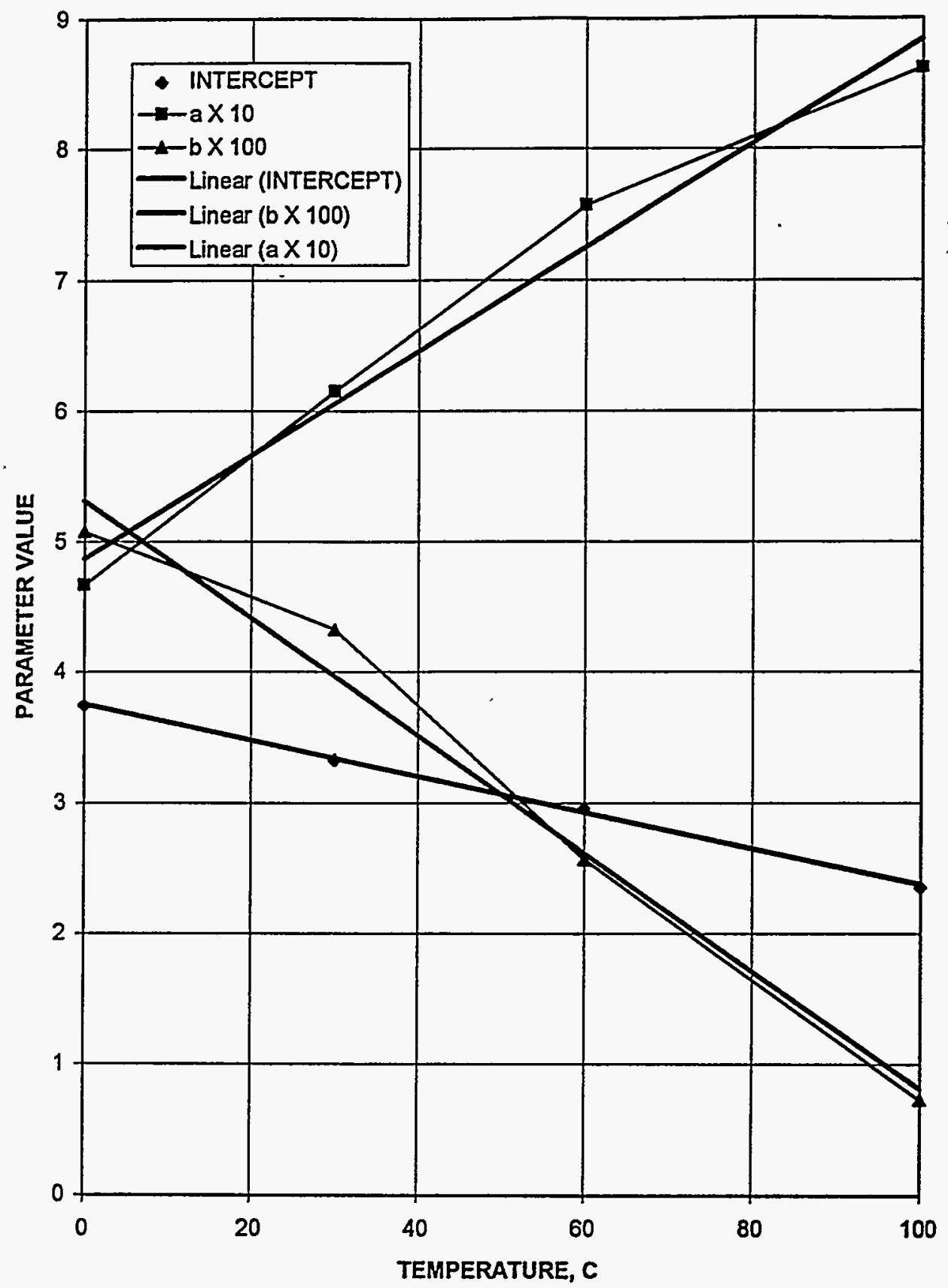

Figure 17. PARAMETER CORRELATION FOR METHANE SORPTION BY ACTIVATED CARBON FIBER. 


\section{CONCLUSIONS}

1. Nitrogen adsorption isotherms at $77 \mathrm{~K}$ still serve as an excellent means of determining the sorption capacity for porous carbons. The existing equipment is capable of low pressure data acquisition in the realm where the effects of micropores are manifest. Most theories to evaluate "miçropore size distributions" assume a rigid solid substrate that is not altered by the sorption process. This assumption is tenuous, at best, for microporous carbons. The merits of these materials to sorb gases is not diminished. The mechanistic interpretation of the process needs to be improved. One must be cautious in modeling the process in terms of porosity whose existence is inferred from such a model. The fact that sorption does occur at these low pressures does not prove the existence of micropores.

2. Sorption isotherms using candidate gases at higher pressures, in the realm of commercial processing, are of prime importance in prediction sorption capacity, energetics of the sorption/desorption processes, and comparison for separation effectiveness. The modified volumetric sorption apparatus shows considerable promise to supply this information in a timely and economical manner.

3. The need for an extensive data base is quite evident. This study has shown that the sorption processes vary markedly with chemical precursor, the physical form of the activated carbon (granules versus fibers). A complete understanding of the activation and efficient industrial utilization of carbons will be very useful and will require a systematic and detailed set of databases. The equipment and expertise of ORNL are well qualified to contribute this information and to disseminate it to the industrial sector in a timely manner.

4. An expansion of the software system is needed to evaluate the sorption processes of interest in the separation and storage programs of interest to DOE. Further enhancement is needed to change sample (isotherm) temperature, acquire isotherm data, change to another temperature, acquire isotherm data, etc. completely unattended without operator 
intervention. Currently each isotherm requires reinitialization by the operator in each instance.

5. The activated carbon fibers produced by the Carbon Materials Technology Group of the Oak Ridge National Laboratory show sorption activity in the range of that is found in commercial activated carbon materials. The carbon fiber materials have considerable merit . based on their physical form (i.e. a reactor bed of fibers has a fixed and stable packing geometry in contrast to that of a granular reactor bed). These are the first efforts in fiber activation, and systematic analyses of the products of various activation techniques will aid in optimizing the products for specific applications in gas purification and storage applications.

6. The staff members of the Carbon Technology Group have been trained to operate the equipment and to present the results in a meaningful manner. Standard operating procedures are in place with the necessary quality control to assure that the results are accurate, meaningful and pertinent. Staff members have acquired a rudimentary understanding of the theory and mathematical analyses that are needed to understand the nature of the sorption processes involved in these highly porous materials. Additional training is needed to expand the analytical capabilities and methodologies of data interpretation to enable a better understanding of the activation processes and the industrial application themselves. 


\section{ACKNOWLEDGMENTS}

This program depended strongly on the participation of M. R. Rogers in every aspect from the transport of the instrument to the vendor, to the detailed mastering of the operation of the equipment and associated computer system, to the data acquisition and dissemination. Timothy Burchell and James Klett produced and provided the activated carbon fibers for analyses and development of the database. O. C. Kopp (Department of Geological Sciences, University of Tennessee) provided valuable and informative discussions throughout the program. 
3M COMPANY

Ceramic Materials Department

201-4N-01 3M Center,

St. Paul, MN 55144

M. A. Leitheiser

AIR PRODUCTS AND CHEMICALS

P.O. Box 538

Allentown, PA 18105

S. W. Dean

ALCOA ALUMINUM COMPANY

100 Technical Drive

Alcoa Center, PA 15069-0001

D. Belitskus

ALLISON GAS TURBINE DIVISION

P.O. Box 420

Indianapolis, IN 46206-0420

P. Khandelwal (Speed Code W-5)

R. A. Wenglarz (Speed Code W-16)

AMA RESEARCH \& DEVELOPMENT CENTER

5950 McIntyre Street

Golden, CO 80403

T. B. Cox

AMOCO PERFORMANCE PRODUCTS, INC.

4500 McGinnis Ferry Road

Alpharetta, GA 30202-3944

G. V. Deshpande

ARGONNE NATIONAL LABORATORY

$9700 \mathrm{~S}$. Cass Avenue

Argonne, IL 60439

W. A. Ellingson

J.P. Singh

ARGONNE NATIONAL LABORATORY-WEST

P.O. Box 2528

Idaho Falls, ID 83403-2528

S. P. Henslee
BABCOCK \& WILCOX

Domestic Fossil Operations

20 South Van Buren Avenue

Barberton, $\mathrm{OH} 44023$

M. Gold

BRITISH COAL CORPORATION

Coal Technology Development Division

Stoke Orchard, Cheltenham

Glocestershire, England GL52 4ZG

J. Oakey

CANADA CENTER FOR MINERAL \& ENERGY TECHNOLOGY

568 Booth Street

Ottawa, Ontario

Canada K1A OG1

R. Winston Revic

Mahi Sahoo

DOE

DOE OAK RIDGE OPERATIONS

P.O.Box 2001

Oak Ridge, TN 37831

Assistant Manager for

Energy Research and Development

DOE

DOE OAK RIDGE OPERATIONS

P. O. Box 2008

Building 4500N, MS 6269

Oak Ridge, TN 37831

M. H. Rawlins

DOE

OFFICE OF BASIC ENERGY SCIENCES

Materials Sciences Division

ER-131

19901 Germantown Road

Germantown, MD 20874-1290

H. M. Kerch 
DOE

IDAHO OPERATIONS OFFICE

P. O. Box 1625

Idaho Falls, ID 83415

J. B. Malmo

DOE

MORGANTOWN ENERGY TECHNOLOGY CENTER

P.O. Box 880

Morgantown, WV 26505

R. C. Bedick

D. C. Cicero

F. W. Crouse, Jr.

N. T. Holcombe

W. J. Huber

J. E. Notestein

DOE

OFFICE OF FOSSIL ENERGY

FE-72

19901 Germantown Road

Germantown, MD 20874-1290

J. P. Carr

DOE

OFFICE OF VEHICLE AND ENERGY R\&D

CE-151 Forrestal Building

Washington, DC 20585

R. B. Schulz

DOE

OFFICE OF SCIENTIFIC AND TECHNICAL INFORMATION

P. O. Box 62

Oak Ridge, TN 37831

For distribution by microfiche as shown in DOE/TIC-4500, Distribution Category:

UC-114 (Coal Based Materials and Components)
DOE

PITTSBURGH ENERGY TECHNOLOGY

CENTER

P.O. Box 10940

Pittsburgh, PA 15236

A. L. Baldwin

G. V. McGurl

T. M. Torkos

DOW CORNING CORPORATION

3901 S. Säginaw Road

Midland, MI 48686-0995

H. Atwell

EC TECHNOLOGIES

3614 Highpoint Drive

San Antonio, TX 78217

D. J. Kenton

ELECTRIC POWER RESEARCH

INSTITUTE

P.O. Box 10412

3412 Hillview Avenue

Palo Alto, CA 94303

W. T. Bakker

J. Stringer

EUROPEAN COMMUNITIES JOINT

RESEARCH CENTRE

Petten Establishment

P.O. Box 2

1755 ZG Petten

The Netherlands

M. Van de Voorde

FIBER MATERIALS, INC.

5 Morin Street

Biddeford, ME 04005-4497

C. Baker

GA TECHNOLOGIES. INC.

P.O. Box 85608

San Diego, CA 92138

T. D. Gulden 
GAS RESEARCH INSTITUTE

8600 West Bryn Mawr Avenue

Chicago, IL 60631

H. S. Meyer

GEORGIA INSTITUTE OF TECHNOLOGY

Materials Science \& Engineering (0245)

Bunger-Henry Building, Room 276

Atlanta, GA 30332-0245

T. L. Starr

KOPPERS INDUSTRIES, INC.

1005 William Pitt Way

Pittsburgh, PA 15238

E. R. McHenry

IDAHO NATIONAL ENGINEERING

LABORATORY

P. O. Box 1625

Idaho Falls, ID 83415

B. H. Rabin

LAVA CRUCIBLE-REFRACTORIES CO.

P.O. Box 278

Zelienople, PA 16063

T. Mulholland

\section{LAWRENCE LIVERMORE NATIONAL}

LABORATORY

P.O. Box 808, L-325

Livermore, CA 94550

W. A. Steele

LOS ALAMOS NATIONAL LABORATORY

P.O. Box 1663

Los Alamos, NM 87545

J. D. Katz

NATIONAL INSTITUTE OF STANDARDS

AND TECHNOLOGY

U.S. Dept. of Commerce

Bldg. 220, Rm A215

Gaithersburg, MD 20899

S. G. Malghan
NATIONAL MATERIALS ADVISORY

BOARD

National Research Council

2101 Constitution Avenue

Washington, DC 20418

K. M. Zwilsky

OAK RIDGE NATIONAL LABORATORY

P.O. Box 2008

Oak Ridge, TN 37831

T. D. Burchell

P. T. Carlson

N. C. Cole

R. R. Judkins

R. A. Lawson (8 copies)

M. R. Upton

OFFICE OF NAVAL RESEARCH

Code 431, 800 N. Quincy Street

Arlington, VA 22217

S. G. Fishman

SANDIA NATIONAL LABORATORIES

Department 6211, MS 0710

Albuquerque, NM 87185

R. J. Buss

G. A. Carlson

A. G. Sault

SHELL DEVELOPMENT COMPANY

P.O. Box 1380

Houston, TX 77251-1380

L. W. R. Dicks

TENNESSEE VALLEY AUTHORITY

Energy Demonstration \& Technology

MR2N58A

Chattanooga, TN 37402-2801

C. M. Huang

THE JOHNS HOPKINS UNIVERSITY

Materials Science \& Engineering

Maryland Hall

Baltimore, MD 21218

R. E. Green, Jr. 
THE MATERIALS PROPERTIES COUNCIL, INC.

United Engineering Center

345 E. Forty-Seventh Street

New York, NY 10017

M. Prager

THE NORTON COMPANY

High Performance Ceramics Division Goddard Road

Northborough, MA 01532-1545

N. Corbin

THE TORRINGTON COMPANY

Advanced Technology Center

59 Field St.

Torrington, CT 06790

W. J. Chmura

UCAR CARBON COMPANY, INC. 12900 Snow Road

Parma, OH 44130

I. Lewis

UNION CARBIDE CORPORATION

Linde Division

P.O. Box 44

175 East Park Drive

Tonawanda, NY 14151-0044

Harry Cheung

UNITED TECHNOLOGIES RESEARCH

CENTER

MS 24, Silver Lane

East Hartford, CT 06108

K. M. Prewo

UNIVERSITY OF KENTUCKY

Center for Applied Energy Research

3572 Iron Works Pike

Lexington, KY 40511-8433

F. Derbyshire
UNIVERSITY OF WASHINGTON

Department of Materials Science and

Engineering

101 Wilson, FB-10

Seattle, WA 98195

T. G. Stoebe

VIRGINIA POLYTECHNIC INSTITUTE \& STATE

UNIVERSITY

Department of Materials Engineering

Blackburg, VA 24601

W. A. Curtin

K. L. Reifsnider

WESTERN RESEARCH INSTITUTE

365 N. 9th Street

P.O. Box 3395

University Station

Laramie, WY 82071

V. K. Sethi

WESTINGHOUSE ELECTRIC CORPORATION

Research and Development Center

1310 Beulah Road

Pittsburgh, PA 15235

S. C. Singhal 